TI 2006-108/3

Tinbergen Institute Discussion Paper

The Effect of Growth and Inequality in Incomes on Health Inequality: Theory and Empirical Evidence from the European Panel

Tom Van Ourtia,c

Eddy Van Doorslaera,c

Xander Koolmana 


\section{Tinbergen Institute}

The Tinbergen Institute is the institute for economic research of the Erasmus Universiteit Rotterdam, Universiteit van Amsterdam, and Vrije Universiteit Amsterdam.

Tinbergen Institute Amsterdam

Roetersstraat 31

1018 WB Amsterdam

The Netherlands

Tel.: $\quad+31(0) 205513500$

Fax: $\quad+31(0) 205513555$

Tinbergen Institute Rotterdam

Burg. Oudlaan 50

3062 PA Rotterdam

The Netherlands

Tel.: $\quad+31(0) 104088900$

Fax: $\quad+31(0) 104089031$

Most TI discussion papers can be downloaded at http:/ /www.tinbergen.nl. 


\title{
The effect of growth and inequality in incomes on health inequality: Theory and empirical evidence from the European Panel
}

\author{
Tom Van Ourti, ${ }^{\mathrm{a}, \mathrm{c},, 1}$, Eddy Van Doorslaer ${ }^{\mathrm{a}, \mathrm{b}, \mathrm{c}}$ and Xander Koolman ${ }^{\mathrm{b}}$ \\ ${ }^{a}$ Erasmus School of Economics, Erasmus University Rotterdam, PB 1738, 3000 DR Rotterdam, The Netherlands \\ ${ }^{b}$ Department of Health Policy and Management, Erasmus University Rotterdam, PB 1738, 3000 DR Rotterdam, \\ The Netherlands \\ ${ }^{c}$ Tinbergen Institute, Burgemeester Oudlaan 50,3062 PA Rotterdam, The Netherlands
}

December 2006

\begin{abstract}
Europe aims at combining income growth with improvements in social cohesion as measured by income and health inequalities. We show that, theoretically, both aims can be reconciled only under very specific conditions concerning the type of growth and the income responsiveness of health. We investigate whether these conditions held in Europe in the nineties using panel data from the European Community Household Panel surveys. We use pooled interval regressions and inequality decompositions to demonstrate that (i) in all countries except Austria, the income elasticity of health is positive and increases with income, and (ii) that income growth was not pro-rich in most EU countries, resulting in little or no reductions in income inequality and modest increases in income-related health inequality in the majority of countries.
\end{abstract}

JEL Classification: D30; D31; I10; I12

Keywords: income inequality, health inequality, income elasticity of health, Europe

\footnotetext{
*Corresponding author. Tel. +31-10-4082681, Fax: +31-10-4089141.

E-mail address: vanourti@few.eur.nl (T. Van Ourti)

${ }^{1}$ This paper derives from the EU funded project "The dynamics of income, health and inequality over the life cycle" (contract QLK6-CT-2002-02297) and from the NETSPAR funded project "Income, health and work across the life cycle". We are grateful to the EC for financial support, to EUROSTAT for access to the ECHP data and to Erik Schokkaert, Joe Tharakan, participants at the ECuity Project workshop in Bonn, at the University of Antwerp and the University of Liège, and the UNU-WIDER conference on Advancing Health Equity for comments on an earlier version of this paper. Tom Van Ourti is a Postdoctoral Fellow of the Netherlands Organisation for Scientific Research - Innovational Research Incentives Scheme - Veni.
} 


\section{Introduction}

Among the fundamental objectives of the European Union are economic and social progress along with improvements in living and working conditions. The EU leaders agreed in Lisbon in 2000 - when setting strategic goals for the current decade - that the Union should strive for economic growth to become "the most competitive and dynamic knowledge-based economy ... with more and better jobs and greater social cohesion" (Atkinson et al., 2002). The Lisbon European Council not only aimed at stimulating economic growth but also at making a decisive impact on the eradication of income poverty and social exclusion and the monitoring of progress towards these goals. ${ }^{2}$ One of the monitoring tools it created was the collection of new sets of comparable longitudinal household level data across all member states, like the European Community Household Panel (ECHP) survey, and its successor, the EU Survey on Income and Living Conditions (EU-SILC). Social exclusion in the EU is broadly defined. It does not only refer to (lack of) income and employment but includes wider social dimensions like housing, education and health. A set of indicators has been developed for monitoring the degree of inequality in income as well as social indicators like health status. ${ }^{3}$

An important question, therefore, is to what extent - and under what conditions - the twin goals of income growth and reduction of social inequalities in health are compatible. ${ }^{4}$ This paper focuses on the consequences of income growth, but - as we show further in the paper these cannot be analysed independently from the effects of evolving income inequalities on social inequalities in health. A second - no less important - question is which countries have managed to achieve these goals, and to what degree. Building on work of Contoyannis and Forster (1999a) and Wagstaff et al. (2003) we develop a decomposition technique that points to the crucial role of the income elasticity of health. If this elasticity is increasing with income, then proportional income growth may - under some conditions - lead to higher income-related health inequalities (hereafter denoted as IRHI). If this were the case, then

\footnotetext{
${ }^{2}$ There are 8 Lisbon strategic goals: 6 on economic performance and 2 on increasing social inclusion.

${ }^{3}$ Among the so-called Level 1 (Laeken) indicators - which consist of a restricted number of lead indicators covering the broad fields of social exclusion - are the ratio of equivalised income of the top and bottom quintile for income inequality (recommendation 15), and the same ratio for the proportion of the population classifying themselves in poor or very poor health (recommendation 23) in Atkinson et al. (2002).

${ }^{4}$ Note that this paper does not fit into the literature on the role of income growth on poverty reduction (e.g. Kraay, 2006) and reduction of income inequality (e.g. Barro, 2000) since we study the joint income-health distribution.
} 
Europe faces a trade-off between these two goals. If, on the other hand, growth goes hand in hand with a reduction in health inequality by income, then greater social inclusion derives as a windfall profit. It turns out that the degree to which income growth occurs disproportionately at higher or lower incomes, and the degree to which health responds to income changes at varying income levels are both crucial elements for the relationship between income growth and inequality and the degree of income-related health inequality.

The paper also analyzes the empirically observed trends in income (inequality) and health (inequality) in European countries. We do this by estimating regression models of health and by using our decomposition technique to relate trends in income growth and income inequality to changes in income-related inequalities in health on the full 8 waves of the ECHP. Although we use longitudinal data, our approach is different from HernándezQuevedo et al. (2006) who analysed the difference between long-term and short-term IRHI using an approach proposed by Jones and Lopez (2004). There is also an epidemiological literature on trends in socioeconomic inequalities in self-assessed health (e.g. Dalstra et al, 2005; Kunst et al, 2005) but in contrast to these earlier empirical papers, we attempt to first theoretically identify the role of changes in the level and distribution of incomes on IRHI before empirically testing these relationships for a large set of European countries.

The paper is organised as follows. Section 2 explains our decomposition technique to analyse the consequences of income growth and income inequality upon social inequalities in health. Section 3 describes the ECHP data set and the empirical models used to implement our decomposition technique of section 2. Empirical results on income elasticities of health and on empirical trends in income, health, inequality and our decomposition technique are presented in section 4 , while section 5 provides a conclusion and discussion. 


\section{Decomposition technique for the relation between the distributions of income and health}

In this section, we present a decomposition technique to examine the impact of changes in the income distribution on the distribution of health. We focus on two aspects of the distribution of health, i.e. the evolution of average health and of IRHI. Despite the analysis being far more complicated for income-related than for pure health inequalities, we did not consider the latter since policy makers are generally more concerned with the socioeconomic gradient in health. We extend the approach proposed by Wagstaff et al. (2003) by allowing for a non-linear relationship between income and health.

\subsection{Decomposing IRHI in a linear framework}

Wagstaff et al. (2003) have proposed a method for decomposing IRHI when health is a linear function of a set of determinants. Each individual $i$ is characterised by her health level $h_{i} \geq 0$, her income level $y_{i} \geq 0$ and a vector of other characteristics $x_{i}$ which could include demographics, etc. The linear relationship allows us - without loss of generality - to assume that $x_{i}$ includes only one variable.

$$
h_{i}=\alpha+\beta y_{i}+\gamma x_{i}
$$

where $\alpha, \beta, \gamma$ are parameters. ${ }^{5}$

We are interested in illuminating the role of income growth on the evolution of both mean health and IRHI. First, the relation between mean health and mean income is straightforward:

$$
H=\alpha+\beta Y+\gamma X
$$

where capital letters denote averages. $\beta$ measures the impact of average income on average

\footnotetext{
${ }^{5}$ Note that the methodology in this section can cope with an error term by incorporating it in $x_{i}$, but for ease of exposition it is neglected here.
} 
health. Consequently, other aspects of the distribution of income (e.g. income inequalities) do not matter.

Like Wagstaff et al. (1991), we will measure IRHI using the concentration index - which is widely used to measure relative IRHI (see e.g. Van Doorslaer et al., 1997; Van Doorslaer and Koolman, 2004; Bleichrodt and van Doorslaer, 2006). The concentration index $C\left(h_{i} \mid y_{i}\right)$ measures the degree of relative inequality and can be written as:

$$
C\left(h_{i} \mid y_{i}\right)=\frac{2 \sum_{i=1}^{n} h_{i} R_{i}}{\sum_{i=1}^{n} h_{i}}-1
$$

where $R_{i}=N^{-1}(i-0.5)$ denotes the fractional rank of income. Wagstaff et al. (2003) have shown that a factor decomposition in the spirit of Shorrocks (1982) can be obtained for the concentration index. ${ }^{6}$ Combining equation (2.3) and (2.1) gives:

$$
C\left(h_{i} \mid y_{i}\right)=\beta \frac{Y}{H} G\left(y_{i}\right)+\gamma \frac{X}{H} C\left(x_{i} \mid y_{i}\right)
$$

where $\beta Y(H)^{-1}$ and $\gamma X(H)^{-1}$ can be interpreted as 'average elasticities', $G\left(y_{i}\right)=C\left(y_{i} \mid y_{i}\right)$ is the Gini index, and $C\left(x_{i} \mid y_{i}\right)$ is the concentration index of $x_{i}$. Equation (2.4) shows that IRHI are a linear function of the income-related inequalities of its determinants weighted by their respective 'average elasticity'. The advantage of their approach for our purposes is that it clearly demonstrates that IRHI is related to average income through the income elasticity but it highlights that other aspects of the distribution of income also matter, in particular the Gini index, the effect of average income on the elasticity of $x_{i}$ (through the effect on $H$ ) and the income rank in $C\left(x_{i} \mid y_{i}\right) \cdot{ }^{7}$

\footnotetext{
6 See also Clarke et al. (2003) and Gravelle (2003).
} 


\subsection{Decomposing changes in IRHI in a non-linear equation}

While the decomposition presented in the previous section has obvious intuitive appeal, it abstracts from the well documented non-linear relationship between income and health, i.e. that health shows diminishing returns to income (e.g. Smith, 1999; Deaton, 2003; Ecob and Smith, 1999; Gerdtham and Johannesson, 2000; Gravelle and Sutton, 2003; Mackenbach et al., 2005). A common approach has been to log-transform $y_{i}$ (e.g. Van Doorslaer and Koolman, 2004) or to use a power function of $y_{i}$ (e.g. Gravelle and Sutton, 2003) in equation (2.1) to preserve linearity in the transformed variable and its decomposition in equation (2.4). This procedure is incapable of informing on the effect of changes in the Gini and in the 'average income elasticity' as it only informs on the contribution of the elasticity and the Gini of the transformed variable (e.g. $\left.\ln \left(y_{i}\right)\right)$. We propose to resolve this problem by recomputing the first term of equation (2.4) in a non-linear setting. We show that it is still possible to make (albeit weaker) inferences on the relative importance of the income elasticity versus income inequality.

While our basic interest lies in equations (2.2) and (2.4), we are not interested in average health and IRHI per se, but rather in their evolution over time. Therefore, we introduce a decomposition of (discrete) time-differences in section 2.3 to disentangle the effects of proportional income growth and income inequality. Our approach bears some resemblance to equation (8) in Wagstaff et al. (2003), which (i) considers a total differential ${ }^{8}$ and (ii) is formulated in a continuous framework, but consequently has the obvious disadvantage that it is only an approximation - valid for very small changes - whereas our approach is exact. This is important since we intend to analyse large changes in average income. In addition, it is easier to deal with non-linearities in our approach (see below). We further assume that equation (2.1) holds in each time period.

First, we allow for a non-linear income effect in equation (2.1) by adding a time subscript:

\footnotetext{
7 Wagstaff et al. (2003) also propose two methods (an Oaxaca-type decomposition and a differential equation based decomposition) to decompose changes in IRHI. We come back to the latter in section 2.2.

${ }^{8}$ Wagstaff et al. (2003) also allow for changes in $\alpha, \beta, \gamma$. Although we keep $\beta$ fixed, the nonlinear relationship of $f()$ allows for different income-effects at different income levels, and consequently at different time periods. Fixing of $\alpha$ and $\gamma$ is less important since we focus on the impact of the distribution of income on the
} 


$$
h_{i t}=\alpha+f\left(y_{i t} ; \beta\right)+\gamma x_{i t}
$$

We allow the function $f()$ and its slope to vary with income and will add additional restrictions below in order to make some analytic predictions. Taking averages, we obtain:

$$
H_{t}=\alpha+\frac{\sum_{i=1}^{n} f\left(y_{i t} ; \beta\right)}{n}+\gamma X_{t}
$$

In contrast to equation (2.2), not only average income, but also the non-linearity of the income profile now matters due to the aggregation of a non-linear income profile. ${ }^{9}$ For example, in the special case of an increasing and concave second order polynomial, one can show that average income increases average health, whereas the variance of income (or income inequality) decreases average health. Doing a similar exercise for IRHI, by introducing a nonlinear income profile, changes equation (2.4) in:

$$
C\left(h_{i t} \mid y_{i t}\right)=\frac{\sum_{i=1}^{n} f\left(y_{i t} ; \beta\right)}{n H_{t}} C\left[f\left(y_{i t} ; \beta\right) \mid y_{i t}\right]+\gamma \frac{X_{t}}{H_{t}} C\left(x_{i t} \mid y_{i t}\right)
$$

Note that the introduction of $f()$ removes the exact relationship between $C\left(h_{i t} \mid y_{i t}\right)$ and the income elasticity and the Gini index. Only if $f\left(y_{i t} ; \beta\right)=\beta y_{i t}$, equation (2.7) reduces to equation (2.4).

Second, introducing discrete time differences to equations (2.6) and (2.7) gives:

distribution of health. Our approach could be generalised to allow for changes in $\alpha, \beta, \gamma$, but consult section 3.1 for our reasons not to do so.

${ }^{9}$ Our assumption does not rely on the literature investigating a direct negative effect of income inequality on individual health. Literature surveys (Wagstaff and van Doorslaer, 2000b; Deaton, 2003) did not find convincing evidence for a direct effect of income inequality on individual health. Moreover, Hildebrand and Van Kerm (2005) - who studied the direct effect of income inequality using the ECHP - found a statistically significant, but very small negative effect. This would imply that our findings for the effect of income inequality can - in the worst case - be interpreted as an upper bound. 


$$
H_{t}-H_{1}=\frac{\sum_{i=1}^{n} f\left(y_{i t} ; \beta\right)-\sum_{i=1}^{n} f\left(y_{i 1} ; \beta\right)}{n}+\gamma\left(X_{t}-X_{1}\right)
$$

$$
C\left(h_{i t} \mid y_{i t}\right)-C\left(h_{i 1} \mid y_{i 1}\right)=\left\{\begin{array}{l}
\frac{\sum_{i=1}^{n} f\left(y_{i t} ; \beta\right)}{n H_{t}} C\left[f\left(y_{i t} ; \beta\right) \mid y_{i t}\right] \\
-\frac{\sum_{i=1}^{n} f\left(y_{i 1} ; \beta\right)}{n H_{1}} C\left[f\left(y_{i 1} ; \beta\right) \mid y_{i 1}\right.
\end{array}\right\}+\left\{\begin{array}{l}
\gamma \frac{X_{t}}{H_{t}} C\left(x_{i t} \mid y_{i t}\right) \\
-\gamma \frac{X_{1}}{H_{1}} C\left(x_{i 1} \mid y_{i 1}\right)
\end{array}\right\}
$$

Equation (2.8) is relatively straightforward, but the effects of proportional income growth (i.e. a change in average income) and the change in income inequality on IRHI are not so easily inferred from equation (2.9). While it is still straightforward to decompose the effect of a change of $x_{i 1}$ to $x_{i t}$ on the change in IRHI into an average elasticity and an inequality effect using the methods in Wagstaff et al. (2003)), this is no longer the case for a change of $y_{i 1}$ to $y_{i t}$.

\subsection{Disentangling proportional income growth from the evolution of income inequality}

Our approach consists of the introduction of two hypothetical health levels which allow us to put more analytic structure on the decompositions in equation (2.8) and (2.9). These hypothetical health levels are $h_{i t}^{p g}$ (pg for proportional growth) and $h_{i t}^{n g}$ (ng for no growth), i.e.

(2.11) $h_{i t}^{n g}=\alpha+f\left(y_{i 1} ; \beta\right)+\gamma x_{i t}$

where $y_{i t}^{p g}=y_{i 1} Y_{t}\left(Y_{1}\right)^{-1}$. Equation (2.10) presents the hypothetical health level that individual $i$ would have had in period $t$ if her income growth had been equal to the actual average growth, but without any changes in income inequality between period $t$ and 1. A similar intuition lies behind the introduction of $h_{i t}^{n g}$, but in contrast to equation (2.10), the income distribution remains unchanged. Note that we could also have introduced $h_{i 1}^{p g}$ and $h_{i 1}^{n g}$, but we 
prefer $t$ as reference period since it seems more natural to evaluate the effects of income changes with the prevailing value of $x_{i t} .{ }^{10}$ Combining equations (2.8), (2.9), (2.10) and (2.11), we now obtain:

$$
H_{t}-H_{1}=\frac{\sum_{i=1}^{n} f\left(y_{i t} ; \beta\right)-\sum_{i=1}^{n} f\left(y_{i t}^{p g} ; \beta\right)}{n}+\frac{\sum_{i=1}^{n} f\left(y_{i t}^{p g} ; \beta\right)-\sum_{i=1}^{n} f\left(y_{i 1} ; \beta\right)}{n}+\gamma\left(X_{t}-X_{1}\right)
$$$$
C\left(h_{i t} \mid y_{i t}\right)-C\left(h_{i 1} \mid y_{i 1}\right)
$$$$
=\underbrace{\frac{\sum_{i=1}^{n} f\left(y_{i t} ; \beta\right)}{n H_{t}} C\left[f\left(y_{i t} ; \beta\right) \mid y_{i t}\right]-\frac{\sum_{i=1}^{n} f\left(y_{i t}^{p g} ; \beta\right)}{n H_{t}^{p g}} C\left[f\left(y_{i t}^{p g} ; \beta\right) \mid y_{i 1}\right]}_{\text {term 1a }}
$$$$
+\underbrace{\frac{\sum_{i=1}^{n} f\left(y_{i t}^{p g} ; \beta\right)}{n H_{t}^{p g}} C\left[f\left(y_{i t}^{p g} ; \beta\right) \mid y_{i 1}\right]-\frac{\sum_{i=1}^{n} f\left(y_{i 1} ; \beta\right)}{n H_{t}^{n g}} C\left[f\left(y_{i 1} ; \beta\right) \mid y_{i 1}\right]}_{\text {term } 1 \mathrm{~b}}
$$$$
+\underbrace{C\left[f\left(y_{i 1} ; \beta\right) \mid y_{i 1}\right]\left[\frac{\sum_{i=1}^{n} f\left(y_{i 1} ; \beta\right)}{n H_{t}^{n g}}-\frac{\sum_{i=1}^{n} f\left(y_{i 1} ; \beta\right)}{n H_{1}}\right]}_{\text {term 1c }}
$$$$
+\underbrace{\gamma \frac{X_{t}}{H_{t}} C\left(x_{i t} \mid y_{i t}\right)-\gamma \frac{X_{t}}{H_{t}^{p g}} C\left(x_{i t} \mid y_{i 1}\right)}_{\text {term 2a }}+\underbrace{C\left(x_{i t} \mid y_{i 1}\right)\left[\gamma \frac{X_{t}}{H_{t}^{p g}}-\gamma \frac{X_{t}}{H_{t}^{n g}}\right]}_{\text {term 2b }}
$$$$
+\underbrace{\gamma \frac{X_{t}}{H_{t}^{n g}} C\left(x_{i t} \mid y_{i 1}\right)-\gamma \frac{X_{1}}{H_{1}} C\left(x_{i 1} \mid y_{i 1}\right)}_{\text {term } 2 \mathrm{c}}
$$

where $C\left(\ldots \mid y_{i t}^{p g}\right) \equiv C\left(\ldots \mid y_{i 1}\right)$. Equation (2.12) clearly shows that the effects of proportional income growth and changes in income inequality are easily separated, and are unambiguous: average health responds elastically/inelastically/unit elastically if equation (2.5) is convex/concave/linear and increasing with income. ${ }^{11}$ With respect to equation (2.13) things are less straightforward. Terms 1a-c disentangle the first term of equation (2.9), while terms

\footnotetext{
${ }^{10}$ Another alternative would be to decompose $C\left(h_{i t} \mid y_{i t}\right)-C\left(h_{i, t-1} \mid y_{i, t-1}\right)$, but it can be shown that the qualitative interpretation of the decomposition is similar. We stick to the comparison with period 1 as it allows for more variation as we decompose over a longer time period.

${ }^{11}$ This result was already shown by Contoyannis and Forster (1999a, 1999b).
} 
2a-c disentangle the second term of equation (2.9). We will show that the a-terms are related to the evolution of income inequality, the b-terms to proportional income growth and the cterms to the evolution of the other determinants of health. In the next subsections we discuss each term in detail.

\subsubsection{Proportional income growth: term $1 b$ and $2 b$}

The influence of proportional income growth on IRHI is summarised by terms $1 \mathrm{~b}$ and $2 \mathrm{~b}$ in equation (2.13), i.e.

$$
\begin{aligned}
& \frac{\sum_{i=1}^{n} f\left(y_{i t}^{p g} ; \beta\right)}{n H_{t}^{p g}} C\left[f\left(y_{i t}^{p g} ; \beta\right) \mid y_{i 1}\right]-\frac{\sum_{i=1}^{n} f\left(y_{i 1} ; \beta\right)}{n H_{t}^{n g}} C\left[f\left(y_{i 1} ; \beta\right) \mid y_{i 1}\right] \\
& C\left(x_{i t} \mid y_{i 1}\right)\left[\gamma \frac{X_{t}}{H_{t}^{p g}}-\gamma \frac{X_{t}}{H_{t}^{n g}}\right]
\end{aligned}
$$

First, note that (2.14) and (2.15) are zero when there is no income growth. Moreover, by definition they are not influenced by changes in income inequality, nor by changes in $x_{i t}$.

Predictions on the sign of (2.14) can be obtained using a result of Contoyannis and Forster (1999a), who considered the special case where income is the sole determinant of health hence (2.14). They show (in their proposition 6) that proportional income growth increases/decreases IRHI if the income elasticity is monotonically rising/falling with income. The intuition for this result can be grasped by considering the linear version of (2.14), i.e.

$$
\frac{\sum_{i=1}^{n} \beta y_{i t}^{p g}}{n H_{t}^{p g}} G\left(\beta y_{i t}^{p g} \mid y_{i 1}\right)-\frac{\sum_{i=1}^{n} \beta y_{i 1}}{n H_{t}^{n g}} G\left(\beta y_{i 1} \mid y_{i 1}\right)
$$

which, after some algebra, reduces to

$$
\frac{\beta\left(Y_{t}-Y_{1}\right)\left(\alpha+\gamma X_{t}\right)}{Y_{1} n H_{t}^{p g} H_{t}^{n g}} \sum_{i=1}^{n}\left[\left(2 R_{i 1}-1\right) y_{i 1}\right]
$$


The term before the sum in (2.17) is a constant for given values of $Y_{t}, Y_{1}, X_{t}$ and positive if $Y_{t}>Y_{1} \cdot{ }^{12}$ The first term in the sum $\left(2 R_{i 1}-1\right)$ is negative for incomes below the median and positive for incomes above the median. Therefore, (2.17) is positive if $Y_{t} \geq Y_{1}$, which establishes the result of Contoyannis and Forster (1999a) for a linear income profile since its income elasticity ${ }^{13}$ always increases with income.

In case of a non-linear income effect, we can generalize the proposition of Contoyannis and Forster (1999a), although the derivation is less intuitive. After some algebra, one can show that $(2.14)$ reduces to:

$$
\sum_{i=1}^{n}\left\{\left(2 R_{i 1}-1\right) \frac{1}{n}\left[\frac{f\left(y_{i t}^{p g} ; \beta\right)}{H_{t}^{p g}}-\frac{f\left(y_{i 1} ; \beta\right)}{H_{t}^{n g}}\right]\right\}
$$

Taking the partial derivative of the term between square brackets gives ${ }^{14}$ :

$$
\frac{\partial\left[\frac{f\left(y_{i t}^{p g} ; \beta\right)}{H_{t}^{p g}}-\frac{f\left(y_{i 1} ; \beta\right)}{H_{t}^{n g}}\right]}{\partial y_{i 1}}=\frac{\partial f\left(y_{i t}^{p g} ; \beta\right)}{\partial y_{i t}^{p g}} \frac{\frac{Y_{T}}{Y_{1}}}{H_{t}^{p g}}-\frac{\partial f\left(y_{i 1} ; \beta\right)}{\partial y_{i 1}} \frac{1}{H_{t}^{n g}}
$$

Multiplying (2.19) by $Y_{1}$ again highlights the crucial role of the income elasticity: the expression in (2.18) is positive/negative if the income elasticity (evaluated at the average values $Y_{t}$ and $Y_{1}$ ) increases/decreases with income. ${ }^{15}$ Because the partial derivatives of

\footnotetext{
${ }^{12}$ It is very plausible to assume that income has a positive effect on health $(\beta>0)$, that average health at income level zero is positive $\left(\alpha+\gamma X_{t}>0\right)$, and that average health and income are positive $Y_{1}, H_{t}^{p g}, H_{t}^{n g}>0$.

${ }^{13}$ Elasticity increases with income since for $h=\alpha+\beta y+\gamma x$, we have that $\left(\partial \varepsilon^{y} / \partial y\right)=h^{-2} \beta(h-\beta y)>0$.

${ }^{14}$ Note that we treat the partial derivatives of $H_{t}^{p g}$ and $H_{t}^{n g}$ to $y_{i 1}$ as zero, which is justified since we only intend to investigate how the term changes if we move up in the income distribution, without changing the income distribution (in other words, keeping $H_{t}^{p g}$ and $H_{t}^{n g}$ fixed).

15

Previous research (e.g. Smith, 1999; Deaton, 2003; Gravelle and Sutton, 2003; Mackenbach et al., 2005) generally suggests that the marginal effect of income on health is positive $(\partial f(y ; \beta) / \partial y)>0$ and declining with income $\left(\delta^{2} f(y ; \beta) / \delta y^{2}\right)<0$ and this is confirmed in (most of) our empirical exercise. Note that concavity does not imply that the income elasticity of health $\varepsilon^{y}$ reduces with income. One can see that it is increasing with income if $\left(\partial \varepsilon^{y} / \partial y\right)=\left(\partial^{2} f(y ; \beta) / \partial y^{2}\right)(y / h) \quad+(\partial f(y ; \beta) / \partial y)(h)^{-1}[1-(\partial f(y ; \beta) / \partial y)(y / h)]>0, \quad$ or
} 
$f\left(y_{i t}^{p g} ; \beta\right)$ and $f\left(y_{i 1} ; \beta\right)$ are at the individual level, we can establish a generalization of the Contoyannis and Forster (1999a) proof: the income elasticity does not have to increase/decrease monotonically. All that is required for (2.18) to be positive/negative is that the sum of $\left(2 R_{i 1}-1\right) \frac{1}{n}\left[\frac{f\left(y_{i t}^{p g} ; \beta\right)}{H_{t}^{p g}}-\frac{f\left(y_{i 1} ; \beta\right)}{H_{t}^{n g}}\right]$ of incomes above the median is larger/smaller than the identical sum of incomes below the median. Loosely speaking, it is sufficient if the income elasticity (evaluated at $y_{i 1}$ ) increases/decreases 'on average' and not at each point of the income profile.

The combination of the results in (2.12) and (2.19) is powerful. It implies that proportional income growth leads to a (welfare improving) average health increase and - depending on the slope of the income elasticity - to a (welfare decreasing/increasing) increase/decrease in relative income-related health inequality. Because this result has only limit applicability, as it only refers to proportional income growth, we abstract from proportional income growth in the next section and focus on income inequality changes.

The above discussion illustrates that the income elasticity is a vital element to understand the evolution of IRHI. However, (2.14) assumes that only income affects health, whereas equation (2.13) allows for an additional determinant $x_{i t}$. It follows - as can be inferred from (2.15) - that proportional income growth (through its effect on $H$ ) also affects the elasticity of $x_{i t}$. Although one can predict that $H_{t}^{p g}$ is larger/smaller than $H_{t}^{n g}$ if the elasticity is rising/decreasing with income, we cannot predict the sign of (2.15), as we do not know the sign of $C\left(x_{i t} \mid y_{i 1}\right) \gamma X_{t}$ a priori.

\subsubsection{Changes in income inequality: term $1 \mathrm{a}$ and $2 \mathrm{a}$}

The effect of changes in income inequality on IRHI is summarised by the terms 1a and 2a in equation (2.13), i.e.

$$
\frac{\sum_{i=1}^{n} f\left(y_{i t} ; \beta\right)}{n H_{t}} C\left[f\left(y_{i t} ; \beta\right) \mid y_{i t}\right]-\frac{\sum_{i=1}^{n} f\left(y_{i t}^{p g} ; \beta\right)}{n H_{t}^{p g}} C\left[f\left(y_{i t}^{p g} ; \beta\right) \mid y_{i 1}\right]
$$

$(\partial f(y ; \beta) / \partial y)(h)^{-1}\left(1-\varepsilon^{y}\right)>-\left(\partial^{2} f(y ; \beta) / \partial y^{2}\right)(y / h)$. Moreover, note that the discussed properties imply that 
(2.21) $\gamma \frac{X_{t}}{H_{t}} C\left(x_{i t} \mid y_{i t}\right)-\gamma \frac{X_{t}}{H_{t}^{p g}} C\left(x_{i t} \mid y_{i 1}\right)$

We start by noting that both expressions are by definition not influenced by proportional income growth, nor by changes in $x_{i t}$. The only relevant determinant is the evolution of income inequality between period 1 and $t$. Clearly, without any change in income inequality, both terms are zero.

One can derive from (2.20) - which keeps average income fixed - that a change in income inequality has an immediate direct effect on IRHI and an effect through the income elasticity. Again, we start disentangling (2.20) by first considering when its linear version is positive:

(2.22) $\frac{G\left(y_{i t}\right)}{G\left(y_{i t}^{p g}\right)}=\frac{G\left(y_{i t}\right)}{G\left(y_{i 1}\right)} \geq \frac{\beta \frac{Y_{t}}{H_{t}}}{\beta \frac{Y_{t}}{H_{t}}}=1$

Equation (2.22) clearly shows that an increase in income inequality contributes to IRHI. In the linear case, the effect through the income elasticity is non-existent as the income elasticity does not change due to a change in income inequality.

Using similar algebra as that used to derive (2.18), we arrive at the corresponding non-linear expression, i.e.:

(2.23) $\frac{1}{n} \sum_{i=1}^{n}\left\{2\left[R_{i t} \frac{f\left(y_{i t} ; \beta\right)}{H_{t}}-R_{i 1} \frac{f\left(y_{i t}^{p g} ; \beta\right)}{H_{t}^{p g}}\right]-\left[\frac{f\left(y_{i t} ; \beta\right)}{H_{t}}-\frac{f\left(y_{i t}^{p g} ; \beta\right)}{H_{t}^{p g}}\right]\right\}$

It can be seen from the $R$-terms that - in contrast to (2.18) - income inequality also affects the fractional rank and thus has a direct effect on (2.20) and that - similar to (2.18) - the income elasticity matters. If the evolution of income inequality is on average in favour of/at the expense of the rich and if the income elasticity is increasing/decreasing with income, one can predict that $(2.23)$ is positive/negative. ${ }^{16}$ Intuitively, this can be understood from a

$\varepsilon^{y}<1$, and thus that the final term between brackets is positive.
${ }^{16}$ We are grateful to Paul Contoyannis for pointing this out. 
comparison between (2.18) and (2.23) which shows that in case of pro-rich (pro-poor) evolving income inequality and an elasticity that increases (decreases) with income, both tendencies reinforce one another. These conditions are sufficient, but not necessary: if these tendencies are opposite, then one cannot a priori predict the sign of (2.23). ${ }^{17}$ Intuitively, the latter means that an increase/decrease in income inequality is offset by local changes in the income elasticity: which of the two effects dominates is then an empirical question.

It is important to add that (2.21) shows that changes in income inequality have two additional effects, i.e. (i) it affects the concentration indices of $x_{i t}$ through differences in the fractional rank and (ii) it affects the 'average elasticity of the $x_{i t}$-determinant' through $H$. The sign of (2.21) cannot be predicted a priori.

It is worth emphasizing that the results in this section imply that - contrary to a common belief $^{18}$ (e.g. Blakely and Wilson, 2006; Avendano, Glymour and Mackenbach, 2006; Dahlgren and Whitehead, 2006) - reductions in income inequality do not necessarily lead to lower IRHI - since there are interactions between the evolution of income inequality and the 'slope of the income elasticity' as soon as income affects health in a non-linear way.

\subsubsection{The importance of other determinants: terms $1 \mathrm{c}$ and $2 \mathrm{c}$}

Terms c of equation (2.13) measure the effect of the change from $x_{i 1}$ to $x_{i t}$. Term 1c measures the effect of this change through $H$ while term 2c summarizes the effect of this change on the 'average elasticity' of $x_{i t}$ and the effect that runs via changes in the concentration index of $x_{i t}$.

$$
C\left[f\left(y_{i 1} ; \beta\right) \mid y_{i 1}\right]\left[\frac{\sum_{i=1}^{n} f\left(y_{i 1} ; \beta\right)}{n H_{t}^{n g}}-\frac{\sum_{i=1}^{n} f\left(y_{i 1} ; \beta\right)}{n H_{1}}\right]
$$

$$
\gamma \frac{X_{t}}{H_{t}^{n g}} C\left(x_{i t} \mid y_{i 1}\right)-\gamma \frac{X_{1}}{H_{1}} C\left(x_{i 1} \mid y_{i 1}\right)
$$

\footnotetext{
${ }^{17}$ Contrary to (2.18) where $y_{i 1}$ and $y_{i t}^{p g}$ are related through $Y_{t} / Y_{1}$, there is no obvious relationship between both income terms $y_{i t}^{p g}$ and $y_{i t}$.

${ }^{18}$ Contoyannis and Forster (1999a) is a notable exception.
} 
Note again that both expressions drop out from equation (2.13) if $x_{i t}$ is constant over time. However, we cannot predict the sign of (2.24) and (2.25) since the signs of $\gamma$ and of $C\left(x_{i t} \mid y_{i 1}\right)$ and $C\left(x_{i 1} \mid y_{i 1}\right)$ are not known a priori. This is not a disadvantage since both expressions only enter equation (2.13) to correct the effect of changes in the income distribution on IRHI for the evolution of other health determinants. In other words, these are just control terms.

In summary, the above approach builds on Wagstaff et al. (2003), but explicitly accounts for a non-linear relationship between income and health, and allows for large income changes. Depending on the restrictions imposed on the non-linear income profile, predictions can be derived on the effects of changes in average income and changes in the variability of individual income. For instance, assuming a concave profile, one can predict a positive effect from proportional income growth and a negative effect from rising income inequality. The picture is more complicated for the effect of changes in the income distribution on the evolution of IRHI. In order to disentangle the effect of proportional income growth from the impact of changes in income inequality, we introduced two hypothetical health levels, i.e. (i) the health level that would prevail in case of a non-changing income distribution and (ii) the health level that would prevail in case of proportional income growth. This enabled us to (i) isolate the effect of changes in the income distribution from changes in the other health determinants, and (ii) to isolate the effect of changes in income inequality from proportional income growth. In both instances there is a direct effect of the change in the income distribution on IRHI, but also an indirect effect through the other health determinants. Building on Contoyannis and Forster (1999a) we showed that the direct effect of proportional income growth depends on the slope of the income elasticity. If this elasticity is rising/decreasing with income 'on average' (see equation (2.18) for the exact condition), IRHI increase/decline. With respect to the direct effect of changes in income inequality, we predict increasing/decreasing IRHI in case of pro-rich/pro-poor evolving income inequality in combination with an income elasticity that increases/decreases with income 'on average' (see equation (2.23) for the exact condition). We find that reductions in income inequality do not always lead to reductions in IRHI if income inequality and the elasticity do not move together 'on average'. In the latter case both have an opposite effect and the net effect is an empirical issue that cannot be resolved a priori. The sign of the indirect effects (both for proportional 
income growth and income inequality) could not be inferred since these depend on the concentration indices and the elasticity of the other health determinants. Obviously, these are not known a priori.

Our empirical analysis has three objectives. First, as introduction, we present estimates of the income elasticity of health and how it varies with income. Because the income elasticity and its slope are very important to determine the consequences of income growth, we use a flexible functional form in the estimation. Secondly, we will examine empirical trends of income growth, income inequality, average health and IRHI in Europe in the nineties. Third, we will use our decomposition technique to isolate the effects of proportional income growth and changing income inequality. 


\section{Data and empirical model specification}

The data used in this paper are taken from the full 8 annual waves (1994-2001) of the European Community Household Panel User Database (ECHP-UDB). The ECHP was designed and coordinated by EUROSTAT, and it contains socioeconomic, demographic and health variables, for a panel of households which only includes individuals aged 16 or older. It used a standardised questionnaire which allows for longitudinal analysis. We use all waves that are available for 13 EU member states: Austria, Belgium, Denmark, Finland, France, Germany, Greece, Ireland, Italy, Netherlands, Portugal, Spain and the United Kingdom. We did not analyze the data for Luxembourg (small sample) and Sweden (no panel data in ECHP). For Germany and the UK, we did not use the ECHP (which only ran from 1994 to 1997, i.e. waves 1 to 3) but instead used the German Socio-economic Panel (GSOEP) and the British Household Panel Survey (BHPS). Austria joined the survey in 1995 (wave 2) and Finland in 1996 (wave 3).

\subsection{Estimating the elasticity of health with respect to income}

The two key variables for this study are health and income. The ECHP income measure is disposable (i.e. after-tax) household income, which is all net monetary income received by the household members during the previous year. It includes income from work (employment and self-employment), private income (from investments and property and private transfers to the household), pensions and other direct social transfers received. No account has been taken of indirect social transfers (e.g. reimbursement of medical expenses), receipts in kind and imputed rent from owner-occupied accommodation. The income variable is (i) converted in Euros by yearly PPPs (see EUROSTAT, 2003) to allow for comparability across countries, and (ii) expressed in constant (1996) prices, i.e. deflated by the harmonised index of consumer

prices (HICP), to allow for comparability across waves. The HICP is an overall indicator of price developments in the Euro area and was taken from the European Central Bank (2000, 2003). ${ }^{19}$ The income variable was further divided by the OECD modified equivalence scale in order to account for household size and composition (giving a weight of 1.0 to the first adult, 0.5 to the second and each subsequent person aged 14 and over, and 0.3 to each child aged 
under 4 in the household).

Self-assessed health (SAH) is measured as the response to an ordered 5-point scale (ranging from very good to very poor) on the question "How is your health in general?" In addition to the mere language differences, the question wording was slightly different in 3 of the 13 countries. For France and Germany, a 6 point, respectively 10 point (health satisfaction) scale was recoded into the common 5 point scale by Eurostat. In the UK, the question wording adds a reference to people of the same age (except for wave 6) (Hernández-Quevedo et al, 2004). Reporting heterogeneity in self-assessed health across cultures and populations is a notable concern (Lindeboom and Van Doorslaer (2004) but as our paper is basically about health trends within countries this is less of a concern here. We have adopted the scaling methods based on interval regression proposed by Van Doorslaer and Jones (2003) and used by Van Doorslaer and Koolman (2004) on the ECHP data. ${ }^{20}$ This approach assumes that there is a stable mapping from the Health Utility Index (HUI) (see e.g. Feeny et al. 2002) to the (latent) variable that determines reported $S A H$ and that this applies not only to Canadian but also to European individuals. While the internal validity of this approach was confirmed in the Canadian data (Van Doorslaer and Jones, 2003), it is not possible to test the external validity on the European data. However, sensitivity analysis using other boundaries has shown that the results are almost identical when the imposed thresholds were derived from other (European) generic measures like the Euroqol (Lauridsen et al, 2004; Lecluyse and Cleemput, 2005).

While the decomposition technique of section 2 is applicable on any estimate of equation (2.5), we would prefer to interpret our estimate of the income effect in this equation as causal, as we intend to investigate the impact of proportional income growth and changing income inequality on average health and IRHI. One could apply a simultaneous structural estimation technique to estimate a Grossman type model (e.g. Wagstaff, 1993), but we have opted for a one equation approach because of its transparency, and since we are only interested in the overall income effect rather than the underlying pathways. For the estimation of our health equation, we have included as covariates - besides income - only demographics like age and gender:

\footnotetext{
${ }^{19}$ We do not use national CPI's since yearly PPP's already eliminate differences in the price evolution between countries. All that remains is a correction for 'average price evolution' in the Euro area, i.e. the HICP.

${ }^{20}$ Thresholds are $0,0.428,0.756,0.897,0.947$, and 1
} 


$$
h_{i t}^{*}=\alpha+f\left(y_{i t} ; \beta\right)+x_{i t}^{\prime} \gamma+\varepsilon_{i t}
$$

where $h_{i t}^{*}$ is the latent health outcome, $\alpha, \beta$ and $\gamma$ are parameters to be estimated, $f\left(y_{i t} ; \beta\right)$ is a non-linear function of income (see below), and $\varepsilon_{i t} \sim N\left(0, \sigma_{\varepsilon}^{2}\right)$. We do not observe $h_{i t}^{*}$, but we do observe $S A H$ and can impose its interval boundaries derived from HUI scores. As a result, its predictions are contained in the $[0,1]$ interval and can be interpreted as (predicted) health utilities on the HUI scale. The vector of covariates $\left(x_{i t}\right)$ includes age dummies (categories: $16-29 ; 30-44 ; 45-59 ; 60-69 ; 70+$ ) for both sexes. We limit the specification to only these covariates on the grounds that these can safely be assumed to be exogenous and that we are mainly interested here in an estimate of the overall income elasticity of health (utility), not in the effects of endogenous variables (like life style or labour choices) that may mediate the effect of income on health. For adults, education would also be an obvious exogenous candidate to include and the ECHP records information on the highest level of general or higher education completed. Nevertheless, we had to exclude education from our regression model as EUROSTAT (2003) notes classification problems related to this variable.

Despite the exogenous covariates and the fact that our income measure refers to disposable household income of the previous year - which makes it less prone to reverse causation bias compared to contemporary income - , our approach does not necessarily solve the endogeneity problem between income and health. Therefore, we have also estimated a dynamic version of equation (3.1) which includes $S A H$ for the previous and the first wave (see e.g. Hurd and Kapteyn (2003), Contoyannis et al. (2004) and Jones et al. (2006) for similar approaches). ${ }^{21}$ As the latter specification captures state dependence, removes any correlation between income and initial health from the estimate of $\beta$, and models income effects on health transitions, it is less likely to reflect reverse causation. A comparison of the latter estimates with the estimates based on equation (3.1) revealed no major differences except for a smaller income effect. The latter finding is obvious given that the dynamic approach effectively models health transitions. We also repeated all other analyses in section 4 (income elasticities, trends of average income, income inequalities, average health, IRHI,

\footnotetext{
${ }^{21}$ Lagged and initial health were included as sets of dummies.
} 
and the decomposition approach explained in section 2) and found no important differences. ${ }^{22}$ Since the dynamic approach did not alter the qualitative interpretations of our analyses, only captures the short run effect of income on health and since the approach based on equation (3.1) does not have to deal with terms based on lagged and initial health - and is therefore easier to explain - we decided to present the latter.

We have run pooled ${ }^{23}$ models on a balanced panel of individuals observed for (up to) 8 waves. We did not consider unbalanced panels for three reasons. First, although the decomposition approach explained in section 2 holds for variable population sizes, it cannot isolate the effects of varying population sizes from the effects of changes in the income distribution. Second, and more importantly, Jones et al. (2006) have shown that health-related nonresponse in the ECHP hardly affects estimates of income effects in health equations, and therefore our restriction to balanced panels seems acceptable. Our restriction to balanced panels does mean that especially the results on time trends only apply to a cohort of individuals. Third, as with the dynamic specification (see footnote 22), we have repeated all analyses in section 4 using an unbalanced panel and found no important differences. ${ }^{24}$

We did not include any time dummies on the grounds that these might pick up some average income changes and moreover, in 9 countries the set of time dummies was jointly not statistically significant. We have also kept the $\beta$ 's fixed across time (see also footnote 8 ). In 7 countries we could not reject the null that interactions between time dummies and the nonlinear income profile are statistically irrelevant. Moreover, in those cases where the null was rejected, almost none of the individual interactions were statistically significant. Note also

\footnotetext{
${ }^{22}$ There is one difference, i.e. the elasticity estimates are lower for the dynamic approach, but reveal a similar pattern. Therefore, we consider it as qualitatively unimportant. Results from the dynamic approach are obtainable from the authors.

${ }^{23}$ We also experimented with random effects panel models in which we parameterised the individual effects as a function of the means of time-varying variables (Chamberlain, 1980). Although the estimated $\beta$ 's were very similar to those of the pooled models, we prefer the pooled specifications as they impose less stringent exogeneity assumptions (see e.g. chapter 15 in Wooldridge, 200).

${ }^{24}$ We found two differences in the analyses based on the unbalanced panel, but consider both as unimportant since the basic messages of this paper are unaffected. Estimates of the evolution of average health show less of a decline and estimates of the trend in IRHI are less increasing. Both findings are not surprising given that we study a cohort in the balanced panel, i.e. there is no healthy refreshment sample and no sample drop out from unhealthy/deceased individuals and the correlation between income and health is plausibly higher within a cohort than across cohorts. We find that the control terms that were explained in section 2.3.3 pick up both effects, while the other terms of our decomposition technique are not affected by using the unbalanced panel.

Also noteworthy is our finding that the estimates of income growth and income inequalities based on an unbalanced panel are largely confirmed by those resulting from the balanced panel which suggests that attrition is not the driving determinant of these findings.
} 
that the non-linear income profile without interactions still allows for differences in the income effect across time. The cross-country differences in health, income and demographics are documented in Table 3.1 which presents unweighted means of all variables for the pooled sample.

Table 3.1: Summary statistics by country

\begin{tabular}{|c|c|c|c|c|c|c|c|c|c|c|c|c|c|}
\hline & Austria & Belgium & Denmark & Finland & France & Germany & Greece & Ireland & Italy & Netherlands & Portugal & Spain & UK \\
\hline M1629 & 0,089 & 0,052 & 0,059 & 0,062 & 0,064 & 0,069 & 0,045 & 0,069 & 0,096 & 0,041 & 0,080 & 0,077 & 0,066 \\
\hline M3044 & 0,141 & 0,173 & 0,163 & 0,147 & 0,148 & 0,167 & 0,126 & 0,142 & 0,141 & 0,167 & 0,121 & 0,128 & 0,146 \\
\hline M4559 & 0,129 & 0,120 & 0,150 & 0,139 & 0,132 & 0,140 & 0,128 & 0,143 & 0,133 & 0,143 & 0,118 & 0,113 & 0,124 \\
\hline M6069 & 0,072 & 0,059 & 0,062 & 0,069 & 0,064 & 0,068 & 0,090 & 0,072 & 0,070 & 0,060 & 0,078 & 0,078 & 0,058 \\
\hline M70+ & 0,049 & 0,050 & 0,047 & 0,031 & 0,053 & 0,032 & 0,068 & 0,055 & 0,046 & 0,048 & 0,062 & 0,067 & 0,053 \\
\hline F1629 & 0,076 & 0,061 & 0,066 & 0,075 & 0,077 & 0,079 & 0,069 & 0,071 & 0,094 & 0,058 & 0,073 & 0,082 & 0,078 \\
\hline F3044 & 0,152 & 0,203 & 0,171 & 0,172 & 0,170 & 0,176 & 0,142 & 0,157 & 0,149 & 0,198 & 0,136 & 0,143 & 0,181 \\
\hline F4559 & 0,138 & 0,131 & 0,162 & 0,182 & 0,142 & 0,140 & 0,137 & 0,151 & 0,137 & 0,146 & 0,142 & 0,131 & 0,152 \\
\hline F6069 & 0,080 & 0,077 & 0,061 & 0,072 & 0,079 & 0,074 & 0,099 & 0,075 & 0,073 & 0,075 & 0,097 & 0,091 & 0,065 \\
\hline $\mathrm{F} 70+$ & 0,074 & 0,073 & 0,058 & 0,051 & 0,070 & 0,055 & 0,096 & 0,064 & 0,061 & 0,064 & 0,091 & 0,091 & 0,077 \\
\hline income & 14631 & 16298 & 15718 & 12948 & 14516 & 15030 & 7836 & 11876 & 10811 & 14264 & 7293 & 9611 & 14962 \\
\hline sahverybad & 0,013 & 0,006 & 0,010 & 0,006 & 0,034 & 0,032 & 0,021 & 0,005 & 0,016 & 0,005 & 0,039 & 0,017 & 0,019 \\
\hline sahbad & 0,058 & 0,035 & 0,040 & 0,054 & 0,038 & 0,138 & 0,074 & 0,022 & 0,092 & 0,037 & 0,194 & 0,104 & 0,076 \\
\hline sahfair & 0,216 & 0,216 & 0,170 & 0,309 & 0,338 & 0,348 & 0,185 & 0,165 & 0,299 & 0,232 & 0,343 & 0,245 & 0,223 \\
\hline sahgood & 0,429 & 0,531 & 0,328 & 0,461 & 0,473 & 0,406 & 0,270 & 0,367 & 0,437 & 0,561 & 0,398 & 0,485 & 0,466 \\
\hline sahverygood & 0,285 & 0,212 & 0,451 & 0,170 & 0,118 & 0,076 & 0,450 & 0,441 & 0,157 & 0,165 & 0,026 & 0,150 & 0,216 \\
\hline $\mathrm{N}$ & 27769 & 24200 & 20352 & 19314 & 54688 & 60160 & 49072 & 22976 & 72288 & 36448 & 56776 & 58456 & 47400 \\
\hline
\end{tabular}

In view of the literature on a non-linear, concave relationship between income and individual health, the discussion on the relevance of equation (2.5) in section 2.2 and the importance of non-linearity for the current paper (i.e. rising versus decreasing income elasticity), we allow for a flexible functional form by implementing polynomial transformations of income. ${ }^{25}$ This allows for the income elasticity of health to decrease with income in some income ranges and increase in others. The order of the polynomial was determined by first, estimating each model with a fifth order polynomial and then reducing the order of the polynomial until a Likelihood Ratio test (1\% significance level) rejected the 'reduced order' against the higher order polynomial.

We did not use the Eurostat-provided cross-sectional individual sampling weights to estimate equation (3.1), but we did for the estimation of the elasticity of health with respect to income (see e.g. chapter 24 in Cameron and Trivedi (2005)):

$$
\hat{\varepsilon}^{y}=\frac{\partial f\left(y_{i t} ; \hat{\beta}\right)}{\partial y_{i t}} \frac{y_{i t}}{\hat{h}_{i t}}
$$

\footnotetext{
${ }^{25}$ We have not used a power function transformation (e.g. Gravelle and Sutton, 2003) as this would entail a maximum likelihood grid search procedure which - in the light of the 13 countries and the interval regression technique - would be unduly time intensive.
} 
where ${ }^{\wedge}$ denotes an estimate and $\hat{h}_{i t}$ is the predicted value of equation (3.1). We computed equation (3.2) for each individual and calculate the (weighted) mean to obtain the average elasticity over all time periods. In order to verify whether the elasticity is increasing/decreasing with income, this procedure was repeated for each income decile for all time periods. ${ }^{26}$ A comparison between the elasticities of the lowest versus highest deciles provides an indication of whether equation (2.19) holds.

\subsection{Estimating trends of average health, income-related health inequalities, average} income and income inequality

With respect to the distribution of (predicted) health (utility), we calculate $\hat{H}_{t}$ and $C\left(\hat{h}_{i t} \mid y_{i t}\right)$ for each $t$. The concentration index of health $C\left(\hat{h}_{i t} \mid y_{i t}\right)$ is computed using a separate OLSregression for each wave $t$. Kakwani et al. (1997) have shown that the point estimate of $\hat{\lambda}_{t}$ in the following equation equals $C\left(\hat{h}_{i t} \mid y_{i t}\right)$.

$$
2 \hat{\sigma}_{R_{t}}^{2} \frac{\hat{h}_{i t}}{\hat{H}_{t}} \sqrt{w_{i}}=\phi_{t} \sqrt{w_{i}}+\lambda_{t} \sqrt{w_{i}} \hat{R}_{i t}+\zeta_{i t}
$$

where $\hat{h}_{i t}$ is the predicted value of equation (3.1), and thus the resulting $C\left(\hat{h}_{i t} \mid y_{i t}\right)$ can be interpreted as income-related inequality in predicted health utility. $\hat{H}_{t}$ is the weighted average of $\hat{h}_{i t}$ in wave $t, w_{i}$ is the sampling weight ${ }^{27}$ of individual $i$ in wave $1, \phi_{t}$ and $\lambda_{t}$ are parameters to be estimated, and $\zeta_{i t}$ is an error term with zero mean. $\hat{R}_{i t}$ is the estimated weighted fractional rank of income in wave $t$ and $\hat{\sigma}_{R_{t}}^{2}=\left[\sum_{i=1}^{n} w_{i}\right]^{-1}\left[\sum_{i=1}^{n} w_{i}\left(\hat{R}_{i t}-0.5\right)^{2}\right]$ is the estimated weighted variance of $\hat{R}_{i t}$ in wave $t$.

\footnotetext{
${ }^{26}$ We also calculated elasticities for each decile in each time period since these are more relevant to get inferences on equation (2.18). However since the results are confirmed by the elasticities for all time periods and since it would overload the paper with additional tables, we decided not to present these results.

${ }^{27}$ Due to the restriction to a balanced panel we applied the first period weights to all subsequent periods.
} 
We estimate two characteristics of the income distribution. First, we calculate the weighted average income in each period $t$. Second, we calculate the Gini index of income in each wave $t$ using equation (3.3) where $\hat{h}_{i t}$ and $\hat{H}_{t}$ have been replaced by respectively $y_{i t}$ and $\hat{Y}_{t}$.

All four indicators (average income, average health, income Gini and health concentration index) describe the evolution for a single cohort. Especially in the case of average health this may differ from the picture that emerges from repeated cross-section samples where births and deaths are included. In a cohort, the average health will decline.

\subsection{The role of proportional income growth and evolving income inequality}

We estimate (weighted) versions of (2.14), (2.15), (2.20), (2.21), (2.24), and (2.25) for each country in each wave $t$, except the first. To compute the terms of our decomposition technique, we need estimates of $H_{t}^{p g}$ and/or $H_{t}^{n g}$ which are the weighted averages of $\hat{h}_{i t}^{p g}$ and $\hat{h}_{i t}^{n g}$. The latter are obtained by substituting $y_{i t}$ by respectively $\hat{y}_{i t}^{p g}$ and $y_{i 1}$ in equation (3.1), and calculating the predicted value of health while keeping the coefficients fixed and the other variables at their actual value. For $\hat{h}_{i t}^{p g}$ we need to generate an estimate for $\hat{y}_{i t}^{p g}$, i.e. $y_{i 1}\left(Y_{t} / Y_{1}\right)$. The latter estimate allows proportional income growth to differ between each period $t$ and the first period., The sums of (2.14)-(2.15), (2.20)-(2.21) and (2.24)-(2.25) provide an indication of the total effect of respectively proportional income growth, income inequality, and the other determinants.

\subsection{Statistical inference on income elasticity and trends}

For statistical inference on the point estimates of the income elasticity at the various deciles,

the trends in average income, the income Gini, average health, the health $\mathrm{CI}$ and its decomposition, we use the bootstrap procedure of Mills and Zandvakili (1997). We draw 100 bootstrap samples ${ }^{28}$ on the level of the individual (i.e. if an individual is drawn in one time period, he is included in all time periods) which corrects the statistical inference for the dependence between time periods, repeat all calculations, and compute 95 percent normal 
confidence intervals for the elasticities and all expressions of the decomposition in section 2.3 .

${ }^{28}$ We did not consider a higher number of bootstrap replications due to the time-intensity of our bootstrap procedure. Nevertheless, we think 100 replications are warranted in our application since we could not reject - at the $5 \%$ level - the null hypothesis of a normal distribution for $92 \%$ of our bootstrap samples. 


\section{Empirical findings}

We first present results on one of the crucial elements for the evolution of average health and income related health inequalities, i.e. the income elasticity of health, then present the trends in average health, IRHI, average income and income inequalities and discuss the findings on the decomposition approach. Due to space limitations, we present full model estimates of the regression model only in Appendix Table 1. The coefficients for the age-gender dummies show the expected signs and magnitudes, i.e. younger and male persons have higher health than older and female respondents. Income coefficients showed a highly non-linear pattern and were (jointly) significant in all specifications and for all countries.

\subsection{Income elasticity of health}

A summary of the income elasticity estimates (averages over all time periods) is presented in Table 4.1 while more details are contained in Appendix Table 2. All elasticities are below one - implying a concave income profile - are positive and increasing with income, except for Austria where the confidence intervals of all deciles overlap. In all other countries, the point estimate of the elasticity starts decreasing only at the highest deciles, but the decline is only statistically relevant for Greece and Ireland.

Table 4.1: summary of income elasticity estimates

\begin{tabular}{|c|c|c|c|c|c|c|c|c|c|c|c|c|c|}
\hline & Austria & Belgium & Denmark & France & Finland & Germany & Greece & Ireland & Italy & Netherlands & Portugal & Spain & UK \\
\hline average & 0,0268 & 0,0137 & 0,0278 & 0,0301 & 0,0207 & 0,0296 & 0,0211 & 0,0212 & 0,0182 & 0,0152 & 0,0370 & 0,0246 & 0,0283 \\
\hline decile 1 & 0,0205 & 0,0065 & 0,0169 & 0,0160 & 0,0130 & 0,0184 & 0,0092 & 0,0160 & 0,0069 & 0,0087 & 0,0156 & 0,0113 & 0,0140 \\
\hline decile 2 & 0,0267 & 0,0094 & 0,0222 & 0,0227 & 0,0170 & 0,0260 & 0,0149 & 0,0196 & 0,0121 & 0,0120 & 0,0256 & 0,0177 & 0,0208 \\
\hline decile 3 & 0,0285 & 0,0109 & 0,0247 & 0,0260 & 0,0187 & 0,0287 & 0,0183 & 0,0216 & 0,0147 & 0,0132 & 0,0309 & 0,0208 & 0,0242 \\
\hline decile 4 & 0,0297 & 0,0123 & 0,0266 & 0,0287 & 0,0201 & 0,0303 & 0,0208 & 0,0233 & 0,0166 & 0,0142 & 0,0350 & 0,0231 & 0,0271 \\
\hline decile 5 & 0,0304 & 0,0135 & 0,0283 & 0,0310 & 0,0211 & 0,0317 & 0,0229 & 0,0248 & 0,0185 & 0,0153 & 0,0387 & 0,0254 & 0,0297 \\
\hline decile 6 & 0,0306 & 0,0146 & 0,0298 & 0,0331 & 0,0222 & 0,0328 & 0,0249 & 0,0258 & 0,0204 & 0,0163 & 0,0420 & 0,0275 & 0,0319 \\
\hline decile 7 & 0,0303 & 0,0158 & 0,0314 & 0,0352 & 0,0233 & 0,0338 & 0,0265 & 0,0259 & 0,0220 & 0,0173 & 0,0453 & 0,0296 & 0,0341 \\
\hline decile 8 & 0,0294 & 0,0173 & 0,0331 & 0,0372 & 0,0242 & 0,0342 & 0,0277 & 0,0251 & 0,0236 & 0,0183 & 0,0488 & 0,0315 & 0,0360 \\
\hline decile 9 & 0,0268 & 0,0195 & 0,0350 & 0,0390 & 0,0249 & 0,0336 & 0,0279 & 0,0225 & 0,0251 & 0,0191 & 0,0522 & 0,0329 & 0,0376 \\
\hline decile 10 & 0,0147 & 0,0173 & 0,0300 & 0,0324 & 0,0220 & 0,0260 & 0,0174 & 0,0077 & 0,0225 & 0,0179 & 0,0362 & 0,0262 & 0,0278 \\
\hline
\end{tabular}

In general, we can fairly safely conclude that the income elasticity is positive and nondecreasing with income over most of the income range. The magnitude of the elasticities is rather low; for example, a doubling of income in Austria, results on average in a 2.68 percent increase in health. This may be related to the fact that (good) health has an upper bound while income is unbounded. Nevertheless, the elasticity differences across deciles are highly 
relevant. Countries with particularly large differences between higher and lower deciles are Belgium, Greece, Italy, Portugal and Spain.

While these elasticities only determine the sign of equations (2.18) and (2.23), the findings suggest that proportional income growth is likely to lead to an increase in average health and IRHI. The decrease - if any - at the highest deciles is not problematic since the elasticities above median income are on average much higher than those below the median. The findings further indicate that a pro-rich (c.q. pro-poor) change in income inequality has a negative (positive) effect on average health and that we only have an unequivocal prediction for the evolution of IRHI in the case of a pro-rich evolution of income inequalities.

4.2. Trends in real incomes and income inequality, and trends in average health and income related health inequalities

Detailed information (including statistical significance) on the trends in average income, income inequality, average health and IRHI for all ECHP countries is presented in the appendix in Appendix Table 3-Appendix Table 15. Here we only discuss some summary figures.

First of all, it is obvious from Figure 4.1 that income growth has been unequal across European countries, and that there have been ups and downs in certain periods, but over the entire period (1994-2001), mean incomes have grown in a statistically significant sense in all countries in real terms. In percentage terms, mean annual real income growth has been particularly strong in Portugal (4\%), Spain (3.6\%), Ireland (3\%), Greece (3\%), UK (2.78\%) and the Netherlands (2\%), while it was below $2 \%$ in the other countries. Recall from section 2.3 that with income elasticities of health (increasing with income), the direct predicted effect of positive real income growth is to lead to rising IRHI, even if income inequality does not rise. 
Figure 4.1: Evolution of average equivalent real income in 1996 Euros, 13 EU countries, 1994-2001

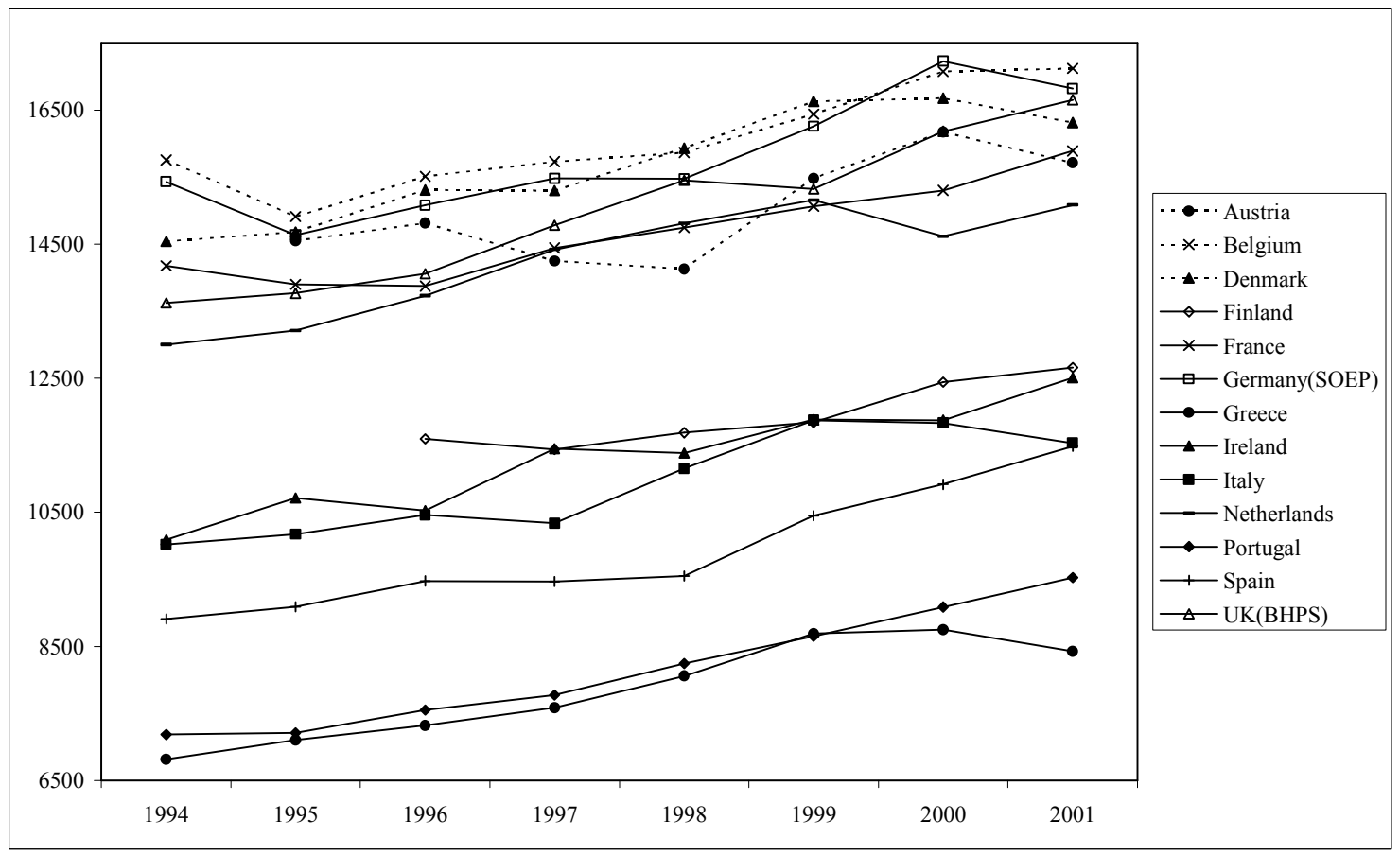

Second, the Gini trends in Figure 4.2 indicate that very few countries have experienced a sustained increase in income inequality over the period 1994-2001. While the trends are by no means monotonic, it is clear from the graph and from the tests (reported in Appendix Table 3Appendix Table 15) that, on the whole, most countries have experienced either pro-poor income growth (Austria, France, Germany, Greece, Italy, Portugal and Spain) or income inequality has remained fairly stable (Belgium ${ }^{29}$, Denmark, Ireland, the Netherlands and the UK). ${ }^{30}$ The sole exception is Finland which shows a statistically significant positive trend: its Gini index was about 10 percent higher in 2001 than in $1996 .{ }^{31}$

While these findings may be seen as somewhat surprising in view of the often reported rising relative income inequality over this period in the OECD context (see e.g. Smeeding, 2002; Kenworthy and Pontusson, 2005), they are consistent with earlier findings reported by Garcia et al. (2004) and Hildebrand and Van Kerm (2005) on the same data and with the series of cross sections compared in Atkinson (2003) and Moran (2005). For example, for the same

\footnotetext{
${ }^{29}$ Lefebure (2005) analysed the data for Belgium in isolation and reported a similar trend.

${ }^{30}$ Because of the non-monotonic trends of income inequality, it is somewhat arbitrary to subdivide the countries into two groups.

${ }^{31}$ The increase in Gini indices is in line with the observed reduction of progressivity of the Finnish tax system (see e.g. Jäntti, 2005). We thank Unto Häkkinen for this suggestion.
} 
period, also Atkinson (2003) reports stable Gini indices for the Netherlands, Italy and the UK, a modest rise in Germany and a strong increase only in Finland.

Given the estimated income elasticities and the trends in income growth, this implies that we cannot make a priori theoretical predictions on the direct effect of income inequality on IRHI, except for Finland where income growth is combined with an elasticity that increases with income and a pro-rich change in income inequality. For the other countries, we can only apply our decomposition technique of section 2.3 to obtain an empirical answer on the role of proportional income growth and income inequality.

Figure 4.2: Evolution of the Gini index of income, 13 EU countries, 1994-2001

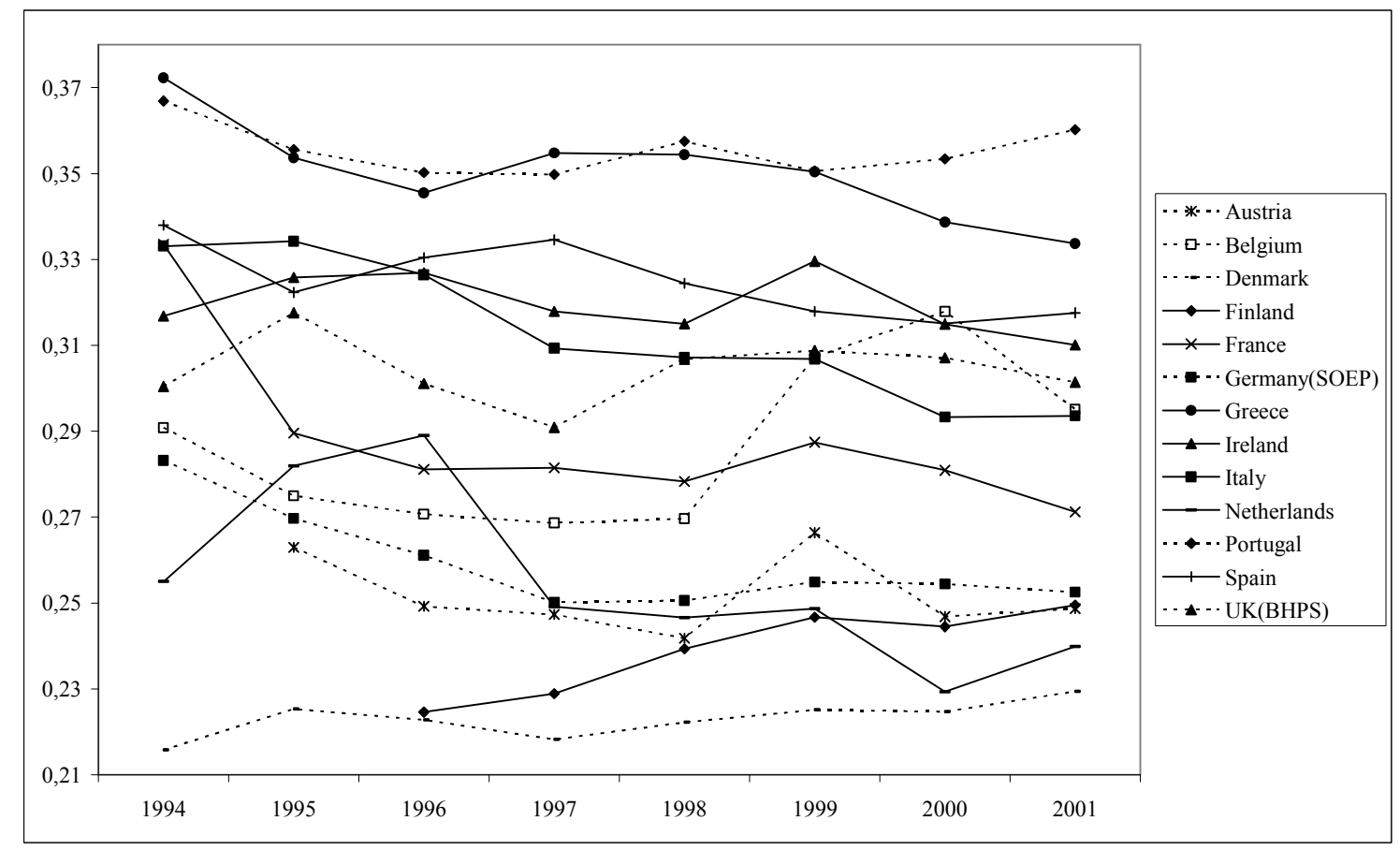

Third, Figure 4.3 describes the trends in average health utility. We have presented the trends as relative deviations from 1996 since reporting heterogeneity in self-assessed health might invalidate comparisons between countries, but probably not within countries. As expected, average health of the ageing cohort decreases but at a slow rate in all countries except the $\mathrm{UK}^{32}$ (see also Appendix Table 3-Appendix Table 15).

\footnotetext{
${ }^{32}$ It is quite likely that the diverging finding for the UK is influenced by the health assessment 'compared to your own age' (see also section 3.1).
} 
Figure 4.3: Evolution of average predicted health utility, 13 EU countries, 1994-2001, $1996=100$

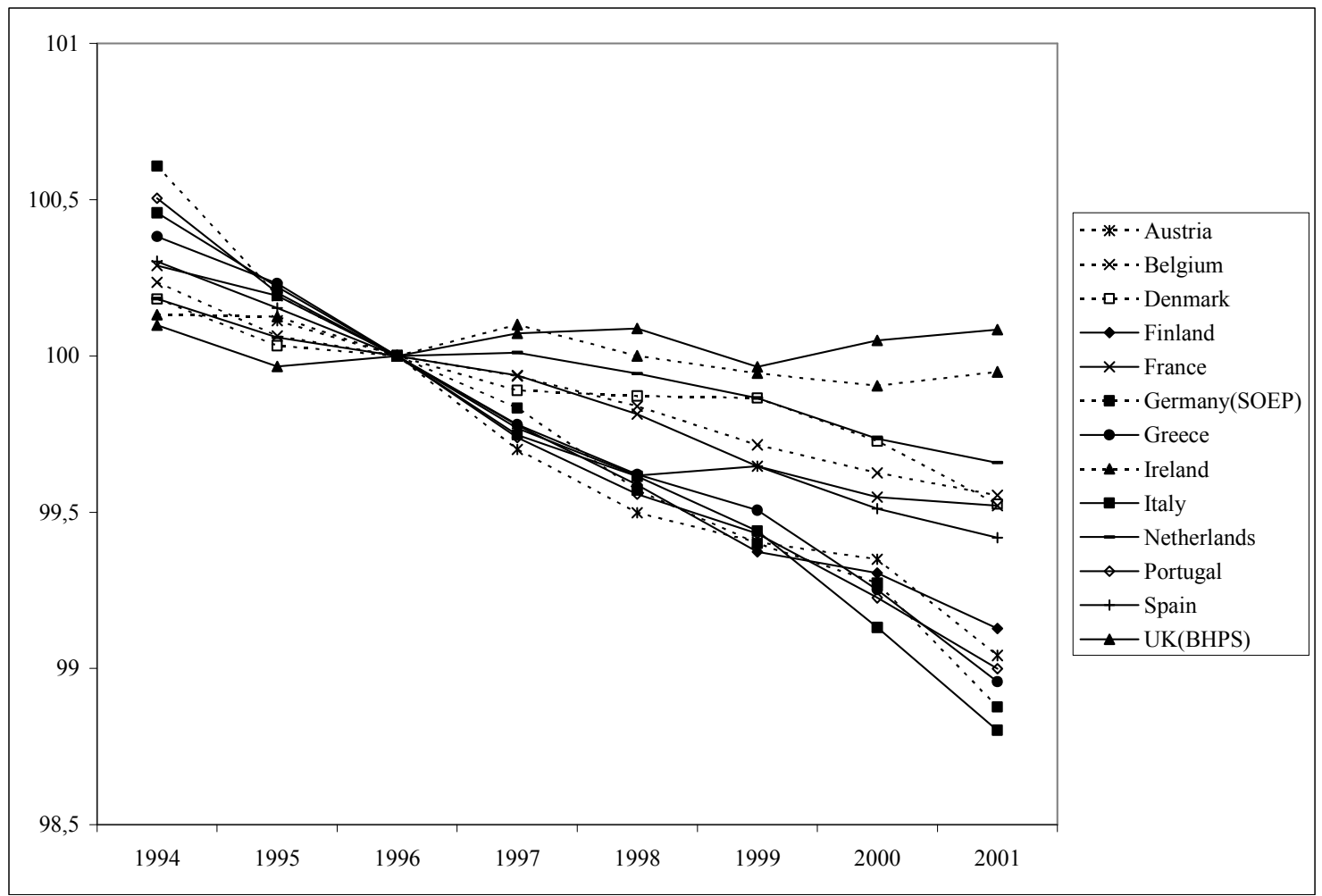

Fourth, in Figure 4.4 we focus on the trends of health concentration indices within countries, with $1996=100$. The positive and increasing CI's indicate that relative IRHI favoured the rich in all countries and increased between 1994 and 2001 in all countries, except Germany and the Netherlands. But they have clearly risen much faster in Finland than in any other European country in this period. 
Figure 4.4: Trends in health concentration indices, 13 EU countries, 1994-2001, 1996=100

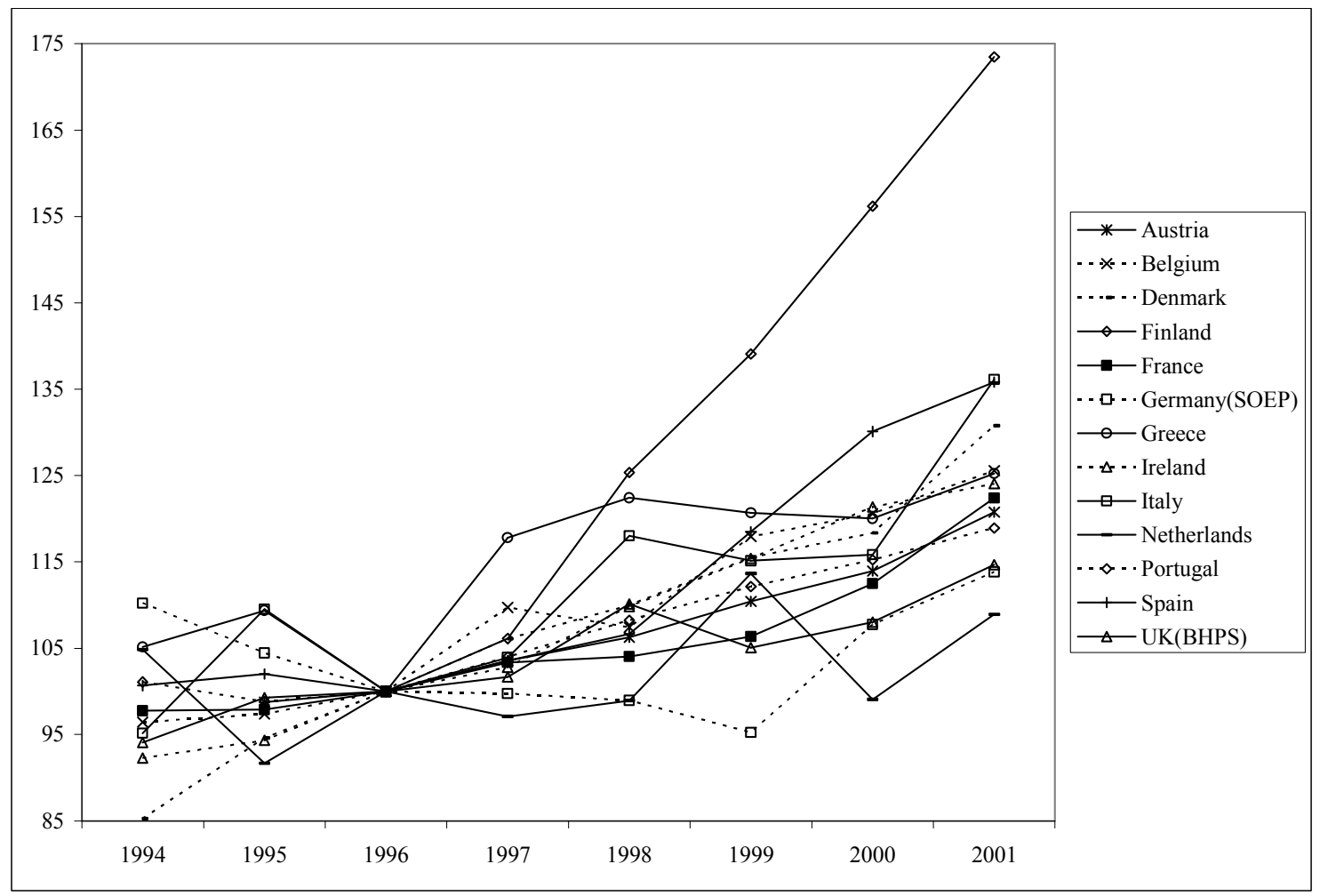

In summary, we find that average income has increased in all countries, whereas relative income inequality remained stable or decreased in all countries except Finland. While average health has deteriorated over time, IRHI has risen more sharply. ${ }^{33}$

\subsection{Mean health and IRHI: the role of income growth and income inequality}

Calculation of equation (2.12) was redundant since one can predict a priori the effect of income growth and income inequality on mean health trends. Since the income elasticities reported in section 4.1 are all between zero and one, the income profile is concave. The income elasticities are also increasing over most of the income range. Consequently, average predicted health utility will respond inelastically to proportional income growth and rising/decreasing income inequalities will have a negative/positive effect on mean health. Since all countries (except Finland) experienced stable or decreasing income inequalities, the

\footnotetext{
${ }^{33}$ It is worth mentioning that for a bounded variable (i.e. with potential range [0,1]) the bounds of the concentration index are determined by the variable mean: the higher the mean, the lower the bounds of the concentration index (see e.g. Wagstaff (2005) and Erreygers (2006)). We used the Wagstaff (2005)
} 
combined health effect of income growth and income inequality was positive between 1994 and 2001.

With respect to the trends in IRHI, the mechanics of our decomposition technique of section 2.3 are somewhat more complex. We will describe the results for all countries but, due to space limitations, we only present the results for the decomposition of the difference between the concentration indices of 2001 and 1994 in Table 4.2. Detailed results for all countries are available in Appendix Table 3-Appendix Table 15.

Table 4.2: Results of our decomposition technique, 1994-2001

\begin{tabular}{|c|c|c|c|c|c|c|c|c|c|c|c|c|c|}
\hline & Austria & Belgium & Denmark & Finland & France & Germany & Greece & Ireland & Italy & Netherlands & Portugal & Spain & UK \\
\hline $\mathrm{Cl}_{1994}$ & 0,0092 & 0,0058 & 0,0067 & 0,0057 & 0,0081 & 0,0088 & 0,0140 & 0,0073 & 0,0053 & 0,0041 & 0,0201 & 0,0094 & 0,0091 \\
\hline$h_{1994}$ & 0,9042 & 0,9090 & 0,9205 & 0,8909 & 0,8745 & 0,8439 & 0,9092 & 0,9263 & 0,8791 & 0,9056 & 0,8370 & 0,8829 & 0,8860 \\
\hline $\mathrm{y}_{1994}$ & 14546 & 15754 & 14539 & 11596 & 14177 & 15431 & 6817 & 10089 & 10020 & 13000 & 7183 & 8911 & 13625 \\
\hline $\mathrm{G}_{1994}$ & 0,2630 & 0,2908 & 0,2158 & 0,2246 & 0,3335 & 0,2832 & 0,3723 & 0,3168 & 0,3331 & 0,2550 & 0,3669 & 0,3380 & 0,3004 \\
\hline $\mathrm{Cl}_{2001}$ & 0,0112 & 0,0076 & 0,0103 & 0,0099 & 0,0102 & 0,0091 & 0,0166 & 0,0099 & 0,0076 & 0,0043 & 0,0237 & 0,0127 & 0,0111 \\
\hline$h_{2001}$ & 0,8946 & 0,9028 & 0,9145 & 0,8831 & 0,8678 & 0,8294 & 0,8962 & 0,9246 & 0,8646 & 0,9008 & 0,8245 & 0,8752 & 0,8859 \\
\hline $\mathrm{y}_{2001}$ & 15711 & 17118 & 16313 & 12660 & 15889 & 16819 & 8426 & 12509 & 11534 & 15081 & 9527 & 11483 & 16652 \\
\hline $\mathrm{G}_{2001}$ & 0,2487 & 0,2951 & 0,2294 & 0,2495 & 0,2712 & 0,2525 & 0,3337 & 0,3101 & 0,2936 & 0,2399 & 0,3602 & 0,3176 & 0,3014 \\
\hline $\mathrm{N}$ & 3967 & 3025 & 2544 & 3219 & 6836 & 7520 & 6134 & 2872 & 9036 & 4556 & 7097 & 7307 & 5925 \\
\hline $\mathrm{Cl}_{2001}-\mathrm{Cl}_{1994}$ & 0,00205 & 0,00175 & 0,00358 & 0,00421 & 0,00206 & 0,00029 & 0,00266 & 0,00252 & 0,00228 & 0,00016 & 0,00355 & 0,00330 & 0,00199 \\
\hline ineq_in & $-0,00030$ & $-0,00026$ & 0,00042 & 0,00037 & $-0,00040$ & $-0,00113$ & $-0,00024$ & 0,00017 & $-0,00068$ & $-0,00033$ & $-0,00093$ & $-0,00062$ & $-0,00059$ \\
\hline elas_in & $-0,00004$ & 0,00024 & 0,00031 & 0,00015 & 0,00038 & 0,00015 & 0,00030 & $-0,00012$ & 0,00043 & 0,00026 & 0,00146 & 0,00081 & 0,00075 \\
\hline past_in & 0,00010 & 0,00003 & 0,00006 & 0,00005 & 0,00012 & 0,00017 & 0,00015 & 0,00004 & 0,00012 & 0,00003 & 0,00035 & 0,00013 & 0,00005 \\
\hline ineq_ot & 0,00258 & 0,00179 & 0,00244 & 0,00362 & 0,00197 & 0,00122 & 0,00214 & 0,00254 & 0,00261 & 0,00039 & 0,00249 & 0,00314 & 0,00168 \\
\hline elas_ot & 0,00000 & 0,00000 & 0,00000 & 0,00000 & 0,00000 & 0,00000 & $-0,00003$ & 0,00000 & 0,00000 & 0,00000 & $-0,00007$ & $-0,00001$ & 0,00000 \\
\hline past_ot & $-0,00028$ & $-0,00005$ & 0,00037 & 0,00002 & $-0,00001$ & $-0,00012$ & 0,00034 & $-0,00010$ & $-0,00020$ & $-0,00018$ & 0,00026 & $-0,00015$ & 0,00011 \\
\hline ineq & 0,00228 & 0,00153 & 0,00286 & 0,00399 & 00157 & 0,00009 & 0,00190 & 0,00271 & 0,00193 & 0,00006 & 0,00156 & 0,00252 & 0,00109 \\
\hline elas & $-0,00004$ & 0,00024 & 0,00030 & 0,00015 & 0,00038 & 0,00014 & 0,00027 & $-0,00013$ & 0,00043 & 0,00026 & 0,00139 & 0,00080 & 0,00074 \\
\hline past & $-0,00018$ & $-0,00002$ & 0,00043 & 0,00007 & 0,00010 & 0,00005 & 0,00050 & $-0,00006$ & $-0,00009$ & $-0,00015$ & 0,00060 & $-0,00002$ & 0,00016 \\
\hline
\end{tabular}

Note: $\quad \mathbf{C I}_{\mathbf{t}}=C\left(h_{i t} \mid y_{i t}\right) ; \mathbf{h}_{\mathbf{t}}=H_{t} ; \mathbf{y}_{\mathbf{t}}=Y_{t} ; \mathbf{G}_{\mathbf{t}}=G\left(y_{i t}\right) ; \mathbf{C I}_{\mathbf{2 0 0 1}}-\mathbf{C I}_{\mathbf{1 9 9 4}}=C\left(h_{i 2001} \mid y_{i 2001}\right)-C\left(h_{i 1994} \mid y_{i 1994}\right)$; ineq_in: equation (2.20); elas_in: equation (2.14); past_in: equation (2.24); ineq_ot: equation (2.21); elas_ot: equation (2.15); past_ot: equation (2.25); ineq: sum of all ineq_terms; elas: sum of all elas_terms; past: sum of all past_terms; sum: sum of all terms; shaded: statistically significantly different from zero at 5\% level. For Austria and Finland, 2001 is compared with 1995 and 1996 respectively.

The term "elas in" is an estimate of equation (2.14). It measures the direct effect of proportional income growth on IRHI, i.e. the effect that runs via the income elasticity. If there is positive/negative income growth between period 1 and $t$, one would expect a positive/negative effect on IRHI if the elasticity increases with income. It is found that equation (2.14) is positive in all periods and countries where there was positive income growth and negative in case of negative income growth, except for Austria, Germany and Ireland where the effects are not statistically significant. Overall, these findings imply that without proportional income growth, the direct effect would be to find smaller IRHI, except in 
Austria, Germany and Ireland. Therefore, the estimates of equation (2.18) confirm our expectations based on the income elasticities in section 4.1 and the positive growth of average incomes in all countries in section 4.2.

The second term for which we were able to derive some theoretical predictions is equation (2.20), i.e. the direct effect of a change in income inequality. In case of an income elasticity increasing with income and pro-rich change in income inequality 'on average', one can predict that IRHI increases. With opposite configurations of income inequality and the elasticity (note that it is the change in elasticity evaluated at $y_{i t}^{p g}$ and $y_{i t}$ that matters), offsetting effects will occur and it is an empirical question which of the two dominates. Only for Finland and Denmark (even though the trend in income inequality is not statistically significant in Denmark), the theoretically predicted effects are observed, i.e. ineq in is positive and significant when the Gini becomes larger. ${ }^{34}$ Furthermore, in the majority of countries, a decreasing Gini has a negative effect on IRHI, which implies that the direct effect of income inequality is more important than the direct offsetting effect through the income elasticity (or that IRHI would have been higher without the concurrent change in income inequality). For some countries both effects seem to balance out, i.e. Belgium, Greece and Ireland. We thus conclude that for the time period considered, income inequality has evolved in the same direction as IRHI (although there are some exceptions) and that only in the case of Finland (and Denmark) we observe the theoretically predictable effect of increasing health inequalities due to the combination of growing income inequality and an elasticity that increases with income. In the majority of countries, opposite effects from proportional income growth and decreasing income inequalities are observed.

Next, we discuss the term "past_in" which estimates equation (2.24), i.e. the effect of changes in the age structure on IRHI (through the effect of health on the income elasticity). This can be considered as a 'control term' measuring the impact of changes in 'other variables. It is nonetheless of interest here as it measures the 'direct' impact of ageing (in a single cohort). Obviously the 'direct' effect of ageing is to increase IRHI as it increases the income elasticity through a reduced mean health.

\footnotetext{
${ }^{34}$ For some countries the Gini also increases in some waves, but without being overall 'pro-rich', i.e. the changes in the income distribution occur mainly among the rich or among the poor. These countries and waves are Austria (wave 6), Belgium (wave 6-8), Italy (wave 2), the Netherlands (wave 2), UK (all waves except 4). Also in Ireland we find an increase in the Gini but this is combined with a decreasing elasticity.
} 
Next, we discuss the term "elas_ot" (cf. equation (2.15), i.e. the indirect effect of proportional income growth on the elasticities of the age-sex structure. The effect runs through the impact of income growth on average health which affects these elasticities. We could not derive a priori predictions for these terms, but find that they all have a very low contribution (in most cases smaller than 0.00000) and are in many cases statistically insignificant.

The term "ineq_ot" (cf. equation (2.21)) summarizes the indirect effect of changing income inequality. There is an indirect effect on the elasticities of the age-sex dummies (through average health) and an indirect effect through reranking on the concentration indices of the same variables. Again, since no theoretical predictions could be derived, this is an empirical question. We observe in most cases a positive sign, although the effect is not significant for Germany and the Netherlands. Its interpretation is complicated since it is determined by the reranking and the effect on the elasticities. ${ }^{35}$ The effect seems to increase over time, which is not surprising as reranking (and the change in elasticities) becomes a more important phenomenon when a longer period is considered (see Appendix Table 3-Appendix Table 15 for more details).

Finally, the term "past_ot" (cf. equation (2.25)) summarizes the effect of changes in the agesex dummies on the elasticities (both through the average of the dummies and average health) and on the concentration indices of these variables. Again, this term is only of limited interest since it enters the decomposition as a "control term". Recall from the discussion of "in_ot" the relevance of this term for issues related to ageing. The term is insignificant for all countries, except the Netherlands.

Table 4.2 (and Appendix Table 3-Appendix Table 15), also shows the sum of all ineq, elas and past terms. These are interesting since they reflect the sum of the direct and indirect effects of respectively income inequality, proportional income growth, and 'ageing'. In the case of opposite indirect and direct effects, they indicate which effects dominate. First, for all

\footnotetext{
${ }^{35}$ Given that the part $\gamma X_{t}$ is negative in our specification (see Appendix Table 1), this term can only be positive if $\frac{C\left(x_{i t} \mid y_{i t}\right)}{H_{t}}<\frac{C\left(x_{i t} \mid y_{i 1}\right)}{H_{t}^{p g}}$. If income inequality decreases, one would expect $H_{t}^{p g}$ to be smaller than $H_{t}$ (due to the positive, but decreasing with income, income profile). It follows that the required inequality always arises if
} 
countries, except Denmark, the total effect of 8 years of ageing is insignificant. Although, the direct effect of ageing was to increase the income elasticity of health, the combination of direct and indirect effects is no longer statistically significant. We may conclude that IRHI is hardly influenced by 8 years of ageing in our data. An alternative interpretation is to consider the term 'past' as a control term that includes age- and sex-related reporting heterogeneity of self-assessed health.

Second, "elas" is in most cases almost identical to elas_in, since the effect of proportional income growth on the elasticity of the other variables is (almost) negligible. This means that positive income growth adds in all countries, except Austria, Germany and Ireland, to an increase in IRHI. This is certainly the most striking finding of our empirical analysis.

Third, the sign of the total effect of income inequality "ineq" is positive, except for Germany and the Netherlands (and Portugal, see Appendix Table 13). This implies that, despite decreasing or stable income inequality, the overall effect has been an increase in IRHI. In other words, the indirect effects seem to dominate for the effect of income inequality. This may not be so surprising given that this term picks up most of the effects of income reranking. Note that for the effect of income growth, the direct effect was most important.

$C\left(x_{i t} \mid y_{i t}\right)$ is not larger than $C\left(x_{i t} \mid y_{i 1}\right)$, i.e. if reranking does not increase income-related inequalities in the other determinants, here age and sex. 


\section{Conclusion and discussion}

This paper set out to try and answer the question to what extent Europe's twin goals of income growth and reduction of social inequalities - as formulated in the Lisbon strategic goals - are compatible, both on theoretical grounds and empirically. In particular, we concentrated on the consequences of changes in the income distribution for changes in the distribution of health by income. We developed a decomposition technique to analyse the role of changes in (proportional) income growth and income inequality on expected trends in income-related health inequality. It was then applied to the empirical analysis of these trends in 13 European countries using 8 waves of European panel data.

The theoretical model indicates that - when the relationship between income and health is concave - proportional income growth increases average health and rising income inequality reduces average health. With respect to trends in IRHI, it is more difficult to isolate the role of income growth and income inequality. Our solution was to introduce two hypothetical health levels. Using this method, we found that income growth and income inequality have a direct and indirect effect on IRHI. A priori sign predictions could be obtained for the direct effects, but not for the indirect effects. Building on Contoyannis and Forster (1999a), we showed that the expected direct effect of proportional income growth depends crucially on the slope of the income elasticity. If this elasticity is rising/decreasing with income 'on average', IRHI increase/decline. With respect to the direct effect of changes in income inequality, we predict increasing/decreasing IRHI in case of 'on average' pro-rich/pro-poor evolving income inequality in combination with an income elasticity that increases/decreases with income 'on average'. The signs of the indirect effects (both for proportional income growth and income inequality) could not be inferred from our decomposition technique and are therefore empirical questions.

In our empirical analysis, we first examined how estimates of the income elasticity of health varied with income since it is an important determinant of the consequences of income growth and income inequality. Using a flexible functional form for the estimation, we found that in all countries, the marginal effect of income on health is positive and decreasing with income. In other words, the income-health relationship is concave, as expected. But secondly, and 
more importantly, the income elasticity of health was nonetheless found to be rising with income ('on average').

Second, we presented trends on income growth, income inequality, average health and IRHI. While between 1994 and 2001, all European countries were found to have experienced real income growth, in most countries this growth was not equally distributed by income level. In all EU countries, income growth was found to be either pro-poor or equally distributed, with one exception: only Finland experienced a clear pro-rich growth. Given this combination of income elasticities rising with income and mostly pro-poor growth, no clear pattern of the impact of income inequality upon income-related health inequality could be predicted $a$ priori. Only for Finland, a steady rise in the concentration index of health could be anticipated. We also presented evidence on the changing distribution of health. Since we analysed a cohort of individuals, average health deteriorated over time, while IRHI increased.

Third, in order to clarify the role and quantify the contribution of proportional income growth and income inequality in the evolution of average health and IRHI, we used our decomposition technique to disentangle direct from indirect effects. We concluded that proportional income growth leads to better average health, and this is true a fortiori when simultaneously income inequality is falling. So economic growth coupled with reduced income inequality is good for mean health levels. However, both the direct and indirect effects of proportional income growth were found to increase IRHI. On the other hand, the direct effect of falling income inequality in Europe led (with a few exceptions) to lower IRHI, while its indirect effect led to increased IRHI. Finally, the model also allows for an analysis of the direct and indirect effects of ageing but we found that the 8 years of ageing in our cohort added next to nothing to IRHI.

So can the twin goals of economic growth and greater social (health) cohesion in the European Union be reconciled? Our analysis suggests that there may be a problem and that Wagstaff's (2002b) hypothesis that developing countries are "swimming against the tide?" by trying to couple growth with reducing relative inequalities may similarly apply to highincome economies like the European. In any case, given the universal observation that everywhere in the 'old' European Union the income elasticity of health rises with income, even proportional growth, leaving income inequality unchanged, will lead to greater IRHI. Had European countries not been able to lower or stabilize their income inequality in the 
nineties, then more countries than only Finland would have experienced sharp increases in socio-economic inequalities in health as a result of the economic growth. Obviously, the overall welfare implications of improved mean health coupled with rising relative IRHI depend on the relative weight given to improvements in the mean versus the distribution. This trade-off can be made explicit by using social welfare type functions (cf Wagstaff, 2002a) but the results depend crucially on the prevailing degree and type of societal aversion to health inequality. Little is known on this empirically and more evidence is needed before these measures can be applied for a welfare analysis of health trends. 


\section{References}

Atkinson A. Income inequality in OECD countries: data and explanations. CESifo Economic Studies 2003; 49; 479-513.

Atkinson A, Cantillon B, Marlier E, Nolan B. Social indicators: The EU and social inclusion. Oxford University Press: Oxford; 2002.

Avendano M, Glymour M, Mackenbach J. Wealth and health in Europe and the United States: a comparative analysis. Paper presented at the UNU-WIDER conference on Advancing Health Equity, 2006.

Barro JR. Inequality and growth in a panel of countries. Journal of Economic Growth 2000; 5: $5-32$.

Blakely T, Wilson N. Shifting dollars, saving lives: What might happen to mortality rates, and socio-economic inequalities in mortality rates, if income was redistributed? Social Science and Medicine 2006; 62; 2024-2034.

Bleichrodt $\mathrm{H}$, van Doorslaer E. A welfare economics foundation for health inequality measurement. Journal of Health Economics 2006, 25(5): 945-957.

Cameron AC, Trivedi PK. Microeconometrics: methods and applications, Cambridge University Press: New York; 2005.

Chamberlain G. Analysis of covariance with qualitative data. Review of Economic Studies $1980 ; 47 ; 225-238$.

Clarke PM, Gerdtham UG, Connelly LB. A note on the decomposition of the health concentration index. Health Economics 2003, 12: 511-516.

Contoyannis P, Forster M. The distribution of health and income: A theoretical framework. Journal of Health Economics 1999a; 18; 605-622

Contoyannis P, Forster M. Our healthier nation? Health Economics 1999b; 8; 289-296

Contoyannis P, Jones A, Rice N. The dynamics of health in the British Household Panel Survey. Journal of Applied Econometrics 2004; 19; 473-503

Crossley TF, Kennedy S. The reliability of self-assessed health status. Journal of Health Economics 2002; 21; 643-658

Dahlgren G, Whitehead M. Levelling up (part 2): a discussion paper on European strategies for tackling social inequities in health. The WHO Regional Office for Europe - World Health Organisation, 2006.

Dalstra JAA, Kunst AE, Geurts JJM, Frenken FJM, Mackenbach JP. Trends in socioeconomic health inequalities in the Netherlands, 1981-1999. Journal of Epidemiology and Community Health 2005; 56; 927-934. 
Deaton A. Health, inequality, and economic development. Journal of economic literature 2003; 41; 113-158.

European Central Bank. Monthly Bulletin December 2000. European Central Bank; Frankfurt; 2000.

Ecob R, Smith G. Income and health: what is the nature of the relationship? Social Science and Medicine 1999; 48; 693-705.

Erreygers G. Correcting the concentration index. mimeo, Department of Economics, University of Antwerp, 2006.

European Central Bank. Monthly Bulletin January 2003. European Central Bank; Frankfurt; 2003.

EUROSTAT, ECHP UDB Description of variables: Data Dictionary, Codebook and Differences between Countries and Waves. European Commission: Luxembourg; 2003.

Feeny D, Furlong W, Torrance GW, Goldsmith CH, Zhu Z, De Pauw S, Denton M, Boyle M. Multiattribute and single-attribute utility functions for the health utilities index mark 3 system. Medical Care 2002; 40(2): 113-128.

Garcia SA, Rodriguez JP, Salas R. The evolution of income inequality in the European Union. Applied Economics 2004; 36; 1399-1408.

Gerdtham UG, Johannesson M Income-related inequality in life-years and quality-adjusted life-years. Journal of health economics 2000; 19; 1007-1026

Gravelle H. Measuring income related inequality in health: standardization and the partial concentration index, Health Economics 2003, 12(10): 803-19.

Gravelle H, Sutton M. Income related inequalities in self assessed health in Britain: 19791995. Journal of Epidemiology Community Health 2003; 57; 125-129.

Groot W. Adaptation and scale of reference bias in self-assessments of quality of life. Journal of Health Economics 2000; 19; 403-420.

Hernández-Quevedo C, Jones AM, Rice N. Reporting bias and heterogeneity in self-assessed health. Evidence from the British Household Panel Survey. University of York discussion paper 2004; 18.

Hernández-Quevedo C, Jones AM, López-Nicolás A, Rice N. Socioeconomic inequalities in health: comparative longitudinal analysis using the European Community Household Panel. Social Science and Medicine 2006, 63: 1246-1261.

Hildebrand V, Van Kerm P. Income inequality and self-rated health status: evidence from the European Community Household Panel, IRISS Working paper series 2005-01.

Hurd M, Kapteyn A. Health, Wealth and the Role of Institutions, Journal of Human Resources 2003; 38; 386-415. 
Jäntti M. The distribution of the tax burden in Finland 1985-2001. mimeo. Abo Akademi University; Turku; Finland, 2005.

Jones AM. Health Econometrics. In: Culyer A, Newhouse J (Eds), Handbook of Health Economics, volume 1. North Holland: Amsterdam; 2000: 265-344.

Jones AM, Koolman X, Rice N. Health-related non-response in the British Household Panel Survey and European Community Household Panel: using inverse probability weighted estimators in nonlinear models, Journal of Royal Statistical Society series A 2006, 169: 543569 .

Jones AM, Lopez A, Measurement and explanation of socioeconomic inequality in health with longitudinal data. Health Economics 2004; 13; 1015-1030.

Kakwani N, Wagstaff A, van Doorslaer E. Socioeconomic inequalities in health: measurement, computation, and statistical inference. Journal of econometrics 1997; 77; 87103.

Kenworthy L, Pontusson J. Rising inequality and the politics of redistribution in affluent countries, Luxemburg Income Study working paper 2005; 400.

Kraay A. When is growth pro-poor? Evidence from a panel of countries. Journal of development economics 2006; 80; 198-227.

Kunst AE, Bos V, Lahelma E, Bartley M, Lissau I, Regidor E, Mielck A, Cardano M, Dalstra JAA, Geurts JJM, Helmert U, Lennartsson C, Ramm J, Spadea T, Stronegger WJ, Mackenbach JP. Trends in socioeconomic inequalities in self-assessed health in 10 European countries. International Journal of Epidemiology 2005; 34; 295-305.

Lauridsen J, Christiansen T, Häkkinen U. Measuring inequality in self-reported health discussion of a recently suggested approach using Finnish data. Health Economics 2004; 13; 725-732.

Lecluyse A, Cleemput I. Making health continuous: implications of different methods on the measurement of inequality. Health Economics 2005; 15; 99-104.

Lefebure S. Nota: suggestie voor het gebruik van de Belgische ECHP-gegevens. Mimeo, Centre for Social Policy; University of Antwerp; Antwerp, 2005.

Lindeboom M, Van Doorslaer E. Cut-point shift and index shift in self-reported health. Journal of Health Economics 2004; 23; 1083-1099.

Mackenbach JP, Martikainen P, Looman CWN, Dalstra JAA, Kunst AE, Lahelma E, and members of the SEdHA working group. The shape of the relationship between income and self-assessed health: an international study, International Journal of Epidemiology 2005; 34; 286-293.

Mills JA, Zandvakili S. Statistical Inference via Bootstrapping for measures of Inequality. Journal of Applied Econometrics 1997, 12: 133-150. 
Moran TP. Bootstrapping the LIS: statistical inference and patterns of inequality in the global North, Luxembourg Income Study working paper2005; 378.

Shorrocks A. Inequality decomposition by factor components. Econometrica $1982 ; 50 ; 193-$ 212.

Smeeding T. Globalization, inequality and the rich countries of the G-20: evidence from the Luxembourg Income Study. Luxembourg Income Study working paper 2002; 320.

Smith J. Healthy bodies and thick wallets: the dual relation between health and economic status. Journal of economic perspectives 1999; 13; 145-166.

Van Doorslaer E, Jones A. Inequalities in self-reported health: validation of a new approach to measurement. Journal of Health Economics 2003; 22; 61-87

Van Doorslaer E, Koolman X. Explaining the differences in income-related health inequalities across European countries. Health Economics 2004; 13; 609-628.

Van Doorslaer E, Koolman X, Jones A. Explaining income-related inequalities in doctor utilisation in Europe. Health Economics 2004; 13; 629-647.

Van Doorslaer E, Wagstaff A, Bleichrodt H, Calonge S, Gerdtham U-G, Gerfin M, Geurts J, Gross L, Häkkinen U, Leu R, O'Donnell O, Propper C, Puffer F, Rodriguez M, Sundberg G, Winkelhake O. Socioeconomic inequalities in health: some international comparisons. Journal of Health Economics 1997; 16; 93-112

Wagstaff A. The demand for health: an empirical reformulation of the Grossman model. Health Economics 1993; 2; 189-198.

Wagstaff A. Inequality aversion, health inequalities and health achievement, Journal of Health Economics 2002a; 21(4): 627-41.

Wagstaff A. Inequalities in health in developing countries: swimming against the tide?, Policy, Research working paper; no. WPS 2795, World Bank, Washington DC, 2002b.

Wagstaff A. The bounds of the concentration index when the variable of interest is binary, with an application to immunization inequality. Health Economics 2005, 14: 429-432.

Wagstaff A, Paci P, Van Doorslaer E. On the measurement of inequalities in health. Social Science and Medicine 1991; 33; 545-557

Wagstaff A, van Doorslaer E. Income inequality and health: what does the literature tell us? Annual Review of Public Health 2000b; 21; 543-567.

Wagstaff A, Van Doorslaer E, Watanabe N. On decomposing the causes of health sector inequalities with an application to malnutrition inequalities in Vietnam. Journal of Econometrics 2003; 112; 207-223.

Wooldridge JM. Econometric analysis of cross section and panel data. The MIT Press; 
Cambridge; 2002. 
Appendix Table 1: health equation estimates

\begin{tabular}{|c|c|c|c|c|c|c|c|c|c|c|c|c|c|}
\hline & Austria & Belgium & Denmark & Finland & France & Germany & Greece & Italy & Ireland & Netherlands & Portugal & Spain & UK \\
\hline M3044 & $-0.018^{* \star}$ & $-0.011^{\star \star}$ & $-0.016^{\star *}$ & $-0.019^{\star \star}$ & $-0.018^{\star \star}$ & $-0.030^{\star \star}$ & $-0.009^{\star \star}$ & $-0.023^{\star \star}$ & $-0.010^{\star \star}$ & $-0.012^{\star \star}$ & $-0.022^{\star \star}$ & $-0.018^{\star *}$ & $-0.013^{\star \star}$ \\
\hline M4559 & $-0.060^{* *}$ & $-0.027^{\star \star}$ & $-0.037^{\star *}$ & $-0.063^{\star \star}$ & $-0.046^{\star \star}$ & $-0.079^{\star \star}$ & $-0.038^{\star \star}$ & $-0.055^{\star \star}$ & $-0.026^{\star \star}$ & $-0.027^{\star \star}$ & $-0.067^{\star \star}$ & $-0.047^{\star *}$ & $-0.027^{* *}$ \\
\hline M6069 & $-0.078^{\star *}$ & $-0.040^{\star *}$ & $-0.052^{\star \star}$ & $-0.087^{\star \star}$ & $-0.069^{\star *}$ & $-0.103^{\star \star}$ & $-0.087^{\star \star}$ & $-0.090^{\star *}$ & $-0.045^{\star \star}$ & $-0.044^{\star \star}$ & $-0.120^{\star \star}$ & $-0.087^{\star *}$ & $-0.041^{* *}$ \\
\hline M70+ & $-0.109^{\star \star}$ & $-0.061^{\star *}$ & $-0.076^{\star \star}$ & $-0.098^{\star *}$ & $-0.093^{\star \star}$ & $-0.125^{\star \star}$ & $-0.136^{* \star}$ & $-0.144^{\star \star}$ & $-0.053^{\star \star}$ & $-0.051^{\star \star}$ & $-0.163^{\star \star}$ & $-0.100^{\star *}$ & $-0.039^{\star \star}$ \\
\hline F1629 & $-0,002$ & $-0,004$ & $-0.007^{\star}$ & $-0.007^{*}$ & $-0,002$ & $-0.008^{\star}$ & $0.005^{\star}$ & $-0.003+$ & $-0,001$ & $-0.008^{\star}$ & 0.001 & $-0,001$ & $-0.011^{\star *}$ \\
\hline F3044 & $-0.017^{\star \star}$ & $-0.019^{\star \star}$ & $-0.023^{\star \star}$ & $-0.022^{\star \star}$ & $-0.025^{\star \star}$ & $-0.035^{\star \star}$ & $-0.012^{\star \star}$ & $-0.030^{\star \star}$ & $-0.011^{\star \star}$ & $-0.021^{\star \star}$ & $-0.032^{\star \star}$ & $-0.020^{\star *}$ & $-0.019^{\star \star}$ \\
\hline F4559 & $-0.057^{\star *}$ & $-0.038^{\star \star}$ & $-0.055^{\star \star}$ & $-0.061^{* *}$ & $-0.056^{\star *}$ & $-0.090^{\star \star}$ & $-0.051^{\star \star}$ & $-0.071^{* \star}$ & $-0.021^{\star *}$ & $-0.038^{\star \star}$ & $-0.095^{\star \star}$ & $-0.065^{\star \star}$ & $-0.041^{* *}$ \\
\hline F6069 & $-0.089^{\star \star}$ & $-0.052^{\star \star}$ & $-0.062^{\star \star}$ & $-0.080^{\star *}$ & $-0.079^{\star *}$ & $-0.112^{\star \star}$ & $-0.109^{\star \star}$ & $-0.116^{\star *}$ & $-0.037^{\star \star}$ & $-0.053^{\star \star}$ & $-0.156^{\star \star}$ & $-0.114^{\star *}$ & $-0.032^{\star *}$ \\
\hline F70+ & $-0.127^{\star *}$ & $-0.070^{\star \star}$ & $-0.092^{\star *}$ & $-0.120^{\star *}$ & $-0.105^{\star \star}$ & $-0.148^{\star \star}$ & $-0.151^{\star \star}$ & $-0.170^{* *}$ & $-0.057^{\star *}$ & $-0.070^{\star \star}$ & $-0.196^{\star *}$ & $-0.134^{\star *}$ & $-0.058^{\star *}$ \\
\hline (eqinc/10000) & $0.042^{\star *}$ & $0.011^{\star *}$ & $0.025^{\star *}$ & $0.027^{\star \star}$ & $0.031^{\star *}$ & $0.032^{\star \star}$ & $0.050^{\star *}$ & $0.024^{\star *}$ & $0.047^{\star \star}$ & $0.016^{\star *}$ & $0.069^{\star *}$ & $0.040^{\star \star}$ & $0.030^{\star *}$ \\
\hline (eqinc/10000^^2 & $-0.010^{* *}$ & $-0.001^{* *}$ & $-0.002^{\star \star}$ & $-0.005^{\star *}$ & $-0.004^{\star \star}$ & $-0.005^{\star \star}$ & $-0.014^{\star \star}$ & $-0.003^{\star \star}$ & $-0.014^{\star *}$ & $-0.002^{\star \star}$ & $-0.015^{\star \star}$ & $-0.008^{* *}$ & $-0.004^{\star *}$ \\
\hline$(\text { eqinc/10000 })^{\wedge} 3$ & $0.001^{* *}$ & $0.000^{\star \star}$ & & $0.000^{\star \star}$ & $0.000^{\star \star}$ & $0.000^{\star \star}$ & $0.001^{\star *}$ & $0.000^{\star \star}$ & $0.002^{\star \star}$ & $0.000^{\star \star}$ & $0.001^{\star \star}$ & $0.001^{\star *}$ & $0.000^{\star *}$ \\
\hline $\begin{array}{l}(\text { eqinc/10000 })^{\wedge} 4 \\
\left(\text { eqinc/10000) }{ }^{\wedge} 5\right.\end{array}$ & $-0.000^{*}$ & $-0.000^{* *}$ & & & $-0.000^{* *}$ & & $-0.000^{* *}$ & & $\begin{array}{l}-0.000^{* *} \\
0.000^{\star *}\end{array}$ & & & $-0.000^{* *}$ & $-0.000^{\star *}$ \\
\hline constant & $0.907^{\star \star}$ & $0.920^{\star \star}$ & $0.92^{\star \star}$ & $0.913^{* *}$ & $0.880^{* *}$ & $0.870^{\star \star}$ & $0.929^{\star *}$ & $0.911^{\star *}$ & $0.914^{\star *}$ & $0.914^{\star \star}$ & $0.861^{* *}$ & $0.902^{\star \star}$ & $0.879^{\star \star}$ \\
\hline$\sigma_{s}^{2}$ & $0.079^{\star *}$ & $0.064^{\star \star}$ & $0.078^{\star \star}$ & $0.068^{\star \star}$ & $0.105^{\star \star}$ & $0.114^{\star \star}$ & $0.094^{\star \star}$ & $0.086^{\star \star}$ & $0.060^{\star \star}$ & $0.063^{\star \star}$ & $0.114^{\star \star}$ & $0.090^{\star \star}$ & $0.098^{\star *}$ \\
\hline Observations & 27769 & 24200 & 20352 & 19314 & 54688 & 60160 & 49072 & 72288 & 22976 & 36448 & 56776 & 58456 & 47400 \\
\hline
\end{tabular}

Notes: + significant at $10 \% ; *$ significant at $5 \% ; * *$ significant at $1 \%$ 


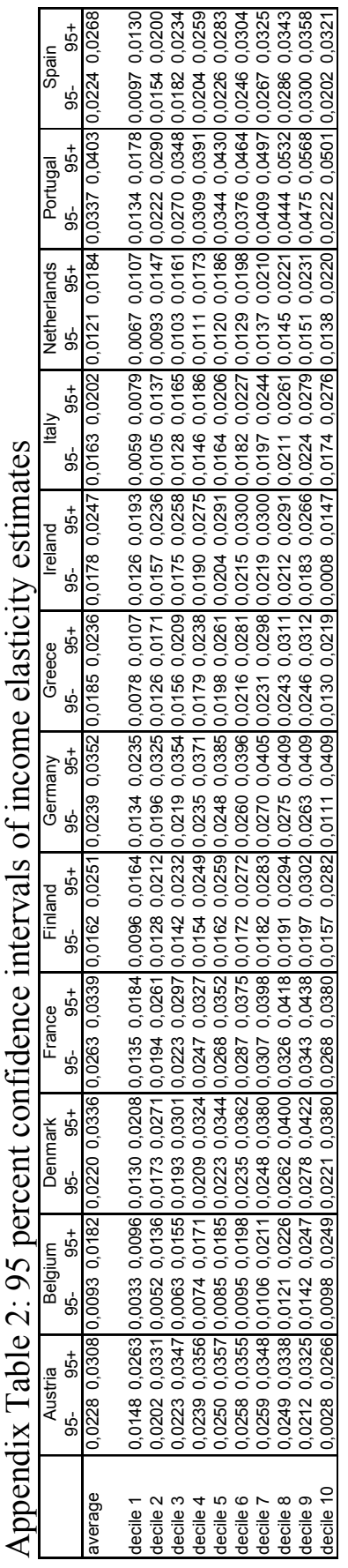


Appendix Table 3: detailed information for Austria

\begin{tabular}{|c|c|c|c|c|c|c|c|c|c|c|c|c|c|c|}
\hline & wave2 & wave3 & wave4 & wave5 & wave6 & wave7 & wave8 & \multicolumn{7}{|c|}{ PAIRWISE TESTS ON DIFFERENCE } \\
\hline $\mathrm{Cl}$ & 0,0092 & 0,0093 & 0,0096 & 0,0099 & 0,0103 & 0,0106 & 0,0112 & $\mathrm{Cl}$ & wave2 & wave3 & wave4 & wave5 & wave6 & wave7 \\
\hline h & 0,9042 & 0,9032 & 0,9005 & 0,8987 & 0,8978 & 0,8973 & 0,8946 & wave3 & 0,0001 & & & & & \\
\hline y & 14546 & 14813 & 14247 & 14129 & 15480 & 16173 & 15711 & wave4 & 0,0004 & 0,0003 & & & & \\
\hline G & 0,2630 & 0,2492 & 0,2473 & 0,2418 & 0,2664 & 0,2468 & 0,2487 & wave5 & 0,0007 & 0,0006 & 0,0003 & & & \\
\hline $\mathrm{N}$ & 3967 & 3967 & 3967 & 3967 & 3967 & 3967 & 3967 & wave6 & 0,0011 & 0,0010 & 0,0006 & 0,0004 & & \\
\hline Clt-Cl1 & & 0,00011 & 0,00044 & 0,00070 & 0,00109 & 0,00141 & 0,00205 & wave7 & 0,0014 & 0,0013 & 0,0010 & 0,0007 & 0,0003 & \\
\hline ineq_in & & $-0,00029$ & $-0,00032$ & $-0,00036$ & $-0,00013$ & $-0,00034$ & $-0,00030$ & wave8 & 0,0020 & 0,0019 & 0,0016 & 0,0014 & 0,0010 & 0,0006 \\
\hline elas_in & & 0,00000 & 0,00000 & 0,00000 & $-0,00003$ & $-0,00007$ & $-0,00004$ & $\mathrm{~h}$ & & & & & & \\
\hline past_in & & 0,00001 & 0,00003 & 0,00004 & 0,00006 & 0,00008 & 0,00010 & wave3 & $-0,0010$ & & & & & \\
\hline ineq_ot & & 0,00050 & 0,00088 & 0,00103 & 0,00132 & 0,00194 & 0,00258 & wave4 & $-0,0037$ & $-0,0027$ & & & & \\
\hline elas_ot & & 0,00000 & 0,00000 & 0,00000 & 0,00000 & $-0,00001$ & 0,00000 & wave5 & $-0,0056$ & $-0,0045$ & $-0,0018$ & & & \\
\hline past_ot & & $-0,00010$ & $-0,00015$ & $-0,00002$ & $-0,00013$ & $-0,00020$ & $-0,00028$ & wave6 & $-0,0064$ & $-0,0054$ & $-0,0027$ & $-0,0008$ & & \\
\hline ineq & & 0,00021 & 0,00056 & 0,00067 & 0,00119 & 0,00160 & 0,00228 & wave7 & $-0,0069$ & $-0,0059$ & $-0,0032$ & $-0,0013$ & $-0,0005$ & \\
\hline elas & & $-0,00001$ & 0,00000 & 0,00000 & $-0,00003$ & $-0,00008$ & $-0,00004$ & wave8 & $-0,0097$ & $-0,0087$ & $-0,0060$ & $-0,0041$ & $-0,0033$ & $-0,0028$ \\
\hline past & & $-0,00009$ & $-0,00012$ & 0,00002 & $-0,00007$ & $-0,00012$ & $-0,00018$ & $\mathrm{y}$ & & & & & & \\
\hline & & & & & & & & wave3 & 267 & & & & & \\
\hline & & & & & & & & wave4 & -299 & -566 & & & & \\
\hline & & & & & & & & wave5 & -417 & -684 & -118 & & & \\
\hline & & & & & & & & wave6 & 934 & 667 & 1233 & 1351 & & \\
\hline & & & & & & & & wave7 & 1627 & 1361 & 1927 & 2045 & 693 & \\
\hline & & & & & & & & wave8 & 1165 & 899 & 1464 & 1583 & 231 & -462 \\
\hline & & & & & & & & G & & & & & & \\
\hline & & & & & & & & wave3 & $-0,0137$ & & & & & \\
\hline & & & & & & & & wave4 & $-0,0157$ & $-0,0019$ & & & & \\
\hline & & & & & & & & wave5 & $-0,0211$ & $-0,0074$ & $-0,0055$ & & & \\
\hline & & & & & & & & wave6 & 0,0034 & 0,0171 & 0,0191 & 0,0245 & & \\
\hline & & & & & & & & wave7 & $-0,0161$ & $-0,0024$ & $-0,0005$ & 0,0050 & $-0,0195$ & \\
\hline & & & & & & & & wave8 & $-0,0143$ & $-0,0005$ & 0,0014 & 0,0069 & $-0,0176$ & 0,0019 \\
\hline
\end{tabular}

Note: $\mathbf{C I}=C\left(h_{i t} \mid y_{i t}\right) ; \mathbf{h}=H_{t} ; \mathbf{y}=Y_{t} ; \mathbf{G}=G\left(y_{i t}\right) ; \mathbf{C I t}-\mathbf{C I} 1=C\left(h_{i t} \mid y_{i t}\right)-C\left(h_{i 1} \mid y_{i 1}\right) ;$ ineq_in: equation (2.20); elas_in: equation (2.14); past_in: equation (2.24); ineq_ot: equation (2.21); elas_ot: equation (2.15); past_ot: equation (2.25); ineq: sum of all ineq_-terms; elas: sum of all elas_-terms; past: sum of all past_terms; shaded: statistically significantly different from zero at $5 \%$ level.

Appendix Table 4: detailed information for Belgium

\begin{tabular}{|c|c|c|c|c|c|c|c|c|c|c|c|c|c|c|c|c|}
\hline & wave1 & wave2 & wave3 & wave4 & wave5 & wave6 & wave7 & wave8 & \multicolumn{8}{|c|}{ PAIRWISE TESTS ON DIFFERENCE } \\
\hline$\overline{\mathrm{Cl}}$ & 0,0058 & 0,0059 & 0,0060 & 0,0066 & 0,0065 & 0,0071 & 0,0073 & $\overline{0,0076}$ & $\mathrm{Cl}$ & wave1 & wave2 & wave3 & wave4 & wave5 & wave6 & wave7 \\
\hline h & 0,9090 & 0,9075 & 0,9069 & 0,9063 & 0,9054 & 0,9043 & 0,9035 & 0,9028 & wave2 & 0,0001 & & & & & & \\
\hline y & 15754 & 14909 & 15510 & 15728 & 15865 & 16437 & 17074 & 17118 & wave3 & 0,0002 & 0,0002 & & & & & \\
\hline G & 0,2908 & 0,2749 & 0,2707 & 0,2687 & 0,2697 & 0,3073 & 0,3178 & 0,2951 & wave4 & 0,0008 & 0,0007 & 0,0006 & & & & \\
\hline $\mathrm{N}$ & 3025 & 3025 & 3025 & 3025 & 3025 & 3025 & 3025 & 3025 & wave5 & 0,0007 & 0,0006 & 0,0004 & $-0,0001$ & & & \\
\hline Clt-Cl1 & & 0,00006 & 0,00021 & 0,00080 & 0,00066 & 0,00129 & 0,00145 & 0,00175 & wave6 & 0,0013 & 0,0012 & 0,0011 & 0,0005 & 0,0006 & & \\
\hline ineq_in & & $-0,00007$ & $-0,00029$ & $-0,00008$ & $-0,00013$ & $-0,00012$ & $-0,00033$ & $-0,00026$ & wave7 & 0,0015 & 0,0014 & 0,0012 & 0,0007 & 0,0008 & 0,0002 & \\
\hline elas_in & & $-0,00015$ & $-0,00004$ & 0,00000 & 0,00002 & 0,00012 & 0,00023 & 0,00024 & wave8 & 0,0018 & 0,0017 & 0,0015 & 0,0010 & 0,0011 & 0,0005 & 0,0003 \\
\hline past_in & & 0,00000 & 0,00001 & 0,00001 & 0,00002 & 0,00002 & 0,00003 & 0,00003 & $\mathrm{~h}$ & & & & & & & \\
\hline ineq_ot & & 0,00029 & 0,00062 & 0,00099 & 0,00089 & 0,00136 & 0,00165 & 0,00179 & wave2 & $-0,0016$ & & & & & & \\
\hline elas_ot & & 0,00000 & 0,00000 & 0,00000 & 0,00000 & 0,00000 & 0,00000 & 0,00000 & wave3 & $-0,0021$ & $-0,0006$ & & & & & \\
\hline past_ot & & $-0,00002$ & $-0,00007$ & $-0,00012$ & $-0,00013$ & $-0,00008$ & $-0,00012$ & $-0,00005$ & wave4 & $-0,0027$ & $-0,0012$ & $-0,0006$ & & & & \\
\hline ineq & & 0,00022 & 0,00032 & 0,00091 & 0,00075 & 0,00124 & 0,00132 & 0,00153 & wave5 & $-0,0036$ & $-0,0020$ & $-0,0015$ & $-0,0009$ & & & \\
\hline elas & & $-0,00015$ & $-0,00004$ & 0,00000 & 0,00002 & 0,00012 & 0,00023 & 0,00024 & wave6 & $-0,0047$ & $-0,0032$ & $-0,0026$ & $-0,0020$ & $-0,0011$ & & \\
\hline past & & $-0,00002$ & $-0,00006$ & $-0,00010$ & $-0,00011$ & $-0,00006$ & $-0,00010$ & $-0,00000$ & wave7 & $-0,0055$ & $-0,0040$ & $-0,0034$ & $-0,0028$ & $-0,0019$ & $-0,0008$ & \\
\hline & & & & & & & & & wave8 & $-0,0062$ & $-0,0046$ & $-0,0040$ & $-0,0035$ & $-0,0026$ & $-0,0015$ & $-0,0007$ \\
\hline & & & & & & & & & $y$ & & & & & & & \\
\hline & & & & & & & & & wave2 & -845 & & & & & & \\
\hline & & & & & & & & & wave3 & -244 & 601 & & & & & \\
\hline & & & & & & & & & wave4 & -25 & 819 & 218 & & & & \\
\hline & & & & & & & & & wave5 & 111 & 956 & 355 & 137 & & & \\
\hline & & & & & & & & & wave6 & 683 & 1528 & 926 & 708 & 571 & & \\
\hline & & & & & & & & & wave7 & 1320 & 2165 & 1564 & 1346 & 1209 & 637 & \\
\hline & & & & & & & & & wave8 & 1364 & 2209 & 1608 & 1390 & 1253 & 681 & 44 \\
\hline & & & & & & & & & $\mathrm{G}$ & & & & & & & \\
\hline & & & & & & & & & wave2 & $-0,0159$ & & & & & & \\
\hline & & & & & & & & & wave3 & $-0,0201$ & $-0,0042$ & & & & & \\
\hline & & & & & & & & & wave4 & $-0,0222$ & $-0,0063$ & $-0,0020$ & & & & \\
\hline & & & & & & & & & wave5 & $-0,0212$ & $-0,0053$ & $-0,0010$ & 0,0010 & & & \\
\hline & & & & & & & & & wave6 & 0,0164 & 0,0323 & 0,0366 & 0,0386 & 0,0376 & & \\
\hline & & & & & & & & & wave7 & 0,0270 & 0,0429 & 0,0471 & 0,0492 & 0,0482 & 0,0106 & \\
\hline & & & & & & & & & wave8 & 0,0043 & 0,0202 & 0,0244 & 0,0264 & 0,0254 & $-0,0122$ & $-0,0227$ \\
\hline
\end{tabular}

Note: $\mathbf{C I}=C\left(h_{i t} \mid y_{i t}\right) ; \mathbf{h}=H_{t} ; \mathbf{y}=Y_{t} ; \mathbf{G}=G\left(y_{i t}\right) ; \mathbf{C I t}-\mathbf{C I 1}=C\left(h_{i t} \mid y_{i t}\right)-C\left(h_{i 1} \mid y_{i 1}\right) ;$ ineq_in: equation (2.20); elas_in: equation (2.14); past_in: equation (2.24); ineq_ot: equation (2.21); elas_ot: equation (2.15); past_ot: equation (2.25); ineq: sum of all ineq_-terms; elas: sum of all elas_terms; past: sum of all past_terms; shaded: statistically significantly different from zero at $5 \%$ level. 
Appendix Table 5: detailed information for Denmark

\begin{tabular}{|c|c|c|c|c|c|c|c|c|c|c|c|c|c|c|c|c|}
\hline & wave1 & wave2 & wave3 & wave4 & wave5 & wave6 & wave7 & wave8 & \multicolumn{8}{|c|}{ PAIRWISE TESTS ON DIFFERENCE } \\
\hline $\mathrm{Cl}$ & 0,0067 & 0,0075 & 0,0079 & 0,0084 & 0,0087 & 0,0091 & 0,0093 & 0,0103 & $\mathrm{Cl}$ & wave1 & wave2 & wave3 & wave4 & wave5 & wave6 & wave7 \\
\hline h & 0,9205 & 0,9192 & 0,9189 & 0,9179 & 0,9177 & 0,9176 & 0,9164 & 0,9145 & wave2 & 0,0007 & & & & & & \\
\hline y & 14539 & 14679 & 15307 & 15297 & 15930 & 16627 & 16675 & 16313 & wave3 & 0,0012 & 0,0004 & & & & & \\
\hline G & 0,2158 & 0,2253 & 0,2228 & 0,2182 & 0,2222 & 0,2251 & 0,2247 & 0,2294 & wave4 & 0,0016 & 0,0009 & 0,0005 & & & & \\
\hline $\mathrm{N}$ & 2544 & 2544 & 2544 & 2544 & 2544 & 2544 & 2544 & 2544 & wave5 & 0,0019 & 0,0012 & 0,0008 & 0,0003 & & & \\
\hline Clt-Cl1 & & 0,00074 & 0,00116 & 0,00164 & 0,00195 & 0,00238 & 0,00260 & 0,00358 & wave6 & 0,0024 & 0,0016 & 0,0012 & 0,0007 & 0,0004 & & \\
\hline ineq_in & & 0,00005 & 0,00010 & 0,00011 & 0,00028 & 0,00035 & 0,00025 & 0,00042 & wave7 & 0,0026 & 0,0019 & 0,0014 & 0,0010 & 0,0007 & 0,0002 & \\
\hline elas_in & & 0,00003 & 0,00014 & 0,00014 & 0,00025 & 0,00035 & 0,00036 & 0,00031 & wave8 & 0,0036 & 0,0028 & 0,0024 & 0,0019 & 0,0016 & 0,0012 & 0,0010 \\
\hline past_in & & 0,00001 & 0,00002 & 0,00002 & 0,00003 & 0,00004 & 0,00005 & 0,00006 & h & & & & & & & \\
\hline ineq_ot & & 0,00060 & 0,00081 & 0,00126 & 0,00131 & 0,00146 & 0,00171 & 0,00244 & wave2 & $-0,0014$ & & & & & & \\
\hline elas_ot & & 0,00000 & 0,00000 & 0,00000 & 0,00000 & 0,00000 & 0,00000 & 0,00000 & wave3 & $-0,0017$ & $-0,0003$ & & & & & \\
\hline past_ot & & 0,00005 & 0,00009 & 0,00011 & 0,00008 & 0,00018 & 0,00025 & 0,00037 & wave4 & $-0,0027$ & $-0,0013$ & $-0,0010$ & & & & \\
\hline ineq & & 0,00065 & 0,000914 & 0,001364 & 0,001594 & 0,001812 & 0,001958 & 0,002855 & wave5 & $-0,0028$ & $-0,0015$ & $-0,0012$ & $-0,0002$ & & & \\
\hline elas & & 0,00003 & 0,000141 & 0,000139 & 0,000244 & 0,000347 & 0,000354 & 0,000302 & wave6 & $-0,0029$ & $-0,0015$ & $-0,0012$ & $-0,0002$ & $-0,0001$ & & \\
\hline past & & 0,00006 & 0,000105 & 0,000136 & 0,000109 & 0,000223 & 0,000294 & 0,000426 & wave7 & $-0,0042$ & $-0,0028$ & $-0,0025$ & $-0,0015$ & $-0,0013$ & $-0,0013$ & \\
\hline & & & & & & & & & wave8 & $-0,0060$ & $-0,0047$ & $-0,0044$ & $-0,0033$ & $-0,0032$ & $-0,0031$ & $-0,0019$ \\
\hline & & & & & & & & & $y$ & & & & & & & \\
\hline & & & & & & & & & wave2 & 139 & & & & & & \\
\hline & & & & & & & & & wave3 & 768 & 629 & & & & & \\
\hline & & & & & & & & & wave4 & 758 & 619 & -10 & & & & \\
\hline & & & & & & & & & wave5 & 1391 & 1252 & 623 & 633 & & & \\
\hline & & & & & & & & & wave6 & 2088 & 1949 & 1320 & 1330 & 697 & & \\
\hline & & & & & & & & & wave7 & 2136 & 1997 & 1368 & 1378 & 745 & 48 & \\
\hline & & & & & & & & & wave8 & 1774 & 1635 & 1006 & 1016 & 383 & -314 & -362 \\
\hline & & & & & & & & & G & & & & & & & \\
\hline & & & & & & & & & wave2 & 0,0095 & & & & & & \\
\hline & & & & & & & & & wave3 & 0,0070 & $-0,0026$ & & & & & \\
\hline & & & & & & & & & wave4 & 0,0024 & $-0,0072$ & $-0,0046$ & & & & \\
\hline & & & & & & & & & wave5 & 0,0064 & $-0,0031$ & $-0,0006$ & 0,0040 & & & \\
\hline & & & & & & & & & wave6 & 0,0093 & $-0,0003$ & 0,0023 & 0,0069 & 0,0029 & & \\
\hline & & & & & & & & & wave7 & 0,0089 & $-0,0006$ & 0,0020 & 0,0066 & 0,0025 & $-0,0003$ & \\
\hline & & & & & & & & & wave8 & 0,0136 & 0,0040 & 0,0066 & 0,0112 & 0,0072 & 0,0043 & 0,0046 \\
\hline
\end{tabular}

Note: $\mathbf{C I}=C\left(h_{i t} \mid y_{i t}\right) ; \mathbf{h}=H_{t} ; \mathbf{y}=Y_{t} ; \mathbf{G}=G\left(y_{i t}\right) ; \mathbf{C I t}-\mathbf{C I} 1=C\left(h_{i t} \mid y_{i t}\right)-C\left(h_{i 1} \mid y_{i 1}\right) ;$ ineq_in: equation (2.20); elas_in: equation (2.14); past_in: equation (2.24); ineq_ot: equation (2.21); elas_ot: equation (2.15); past_ot: equation (2.25); ineq: sum of all ineq_-terms; elas: sum of all elas_terms; past: sum of all past_-terms; shaded: statistically significantly different from zero at $5 \%$ level.

Appendix Table 6: detailed information for Finland

\begin{tabular}{|c|c|c|c|c|c|c|c|c|c|c|c|c|}
\hline & wave3 & wave4 & wave5 & wave6 & wave7 & wave8 & PAIRWI & TESTS OI & DIFFERE & VCE & & \\
\hline $\mathrm{Cl}$ & 0,0057 & 0,0061 & 0,0072 & 0,0080 & 0,0090 & 0,0099 & $\mathrm{Cl}$ & wave3 & wave4 & wave5 & wave6 & wave7 \\
\hline h & 0,8909 & 0,8889 & 0,8872 & 0,8853 & 0,8847 & 0,8831 & wave4 & 0,0004 & & & & \\
\hline y & 11596 & 11433 & 11685 & 11839 & 12444 & 12660 & wave5 & 0,0015 & 0,0011 & & & \\
\hline G & 0,2246 & 0,2289 & 0,2393 & 0,2467 & 0,2445 & 0,2495 & wave6 & 0,0022 & 0,0019 & 0,0008 & & \\
\hline $\mathrm{N}$ & 3219 & 3219 & 3219 & 3219 & 3219 & 3219 & wave7 & 0,0032 & 0,0029 & 0,0018 & 0,0010 & \\
\hline Clt-Cl1 & & 0,00035 & 0,00145 & 0,00224 & 0,00322 & 0,00421 & wave8 & 0,0042 & 0,0039 & 0,0028 & 0,0020 & 0,0010 \\
\hline ineq_in & & 0,00012 & 0,00029 & 0,00035 & 0,00032 & 0,00037 & $\mathrm{~h}$ & & & & & \\
\hline elas_in & & $-0,00003$ & 0,00001 & 0,00004 & 0,00012 & 0,00015 & wave4 & $-0,00198$ & & & & \\
\hline past_in & & 0,00001 & 0,00002 & 0,00003 & 0,00004 & 0,00005 & wave5 & $-0,00368$ & $-0,0017$ & & & \\
\hline ineq_ot & & 0,00028 & 0,00107 & 0,00154 & 0,00246 & 0,00362 & wave6 & $-0,00558$ & $-0,0036$ & $-0,0019$ & & \\
\hline elas_ot & & 0,00000 & 0,00000 & 0,00000 & 0,00000 & 0,00000 & wave7 & $-0,00619$ & $-0,00422$ & $-0,00251$ & $-0,00061$ & \\
\hline past_ot & & $-0,00003$ & 0,00006 & 0,00028 & 0,00028 & 0,00002 & wave8 & $-0,00778$ & $-0,0058$ & $-0,0041$ & $-0,0022$ & $-0,00158$ \\
\hline ineq & & 0,00040 & 0,00136 & 0,00190 & 0,00278 & 0,00399 & $y$ & & & & & \\
\hline elas & & $-0,00003$ & 0,00001 & 0,00004 & 0,00012 & 0,00015 & wave4 & -163 & & & & \\
\hline past & & $-0,00002$ & 0,00008 & 0,00031 & 0,00032 & 0,00007 & wave5 & 89 & 252 & & & \\
\hline & & & & & & & wave6 & 243 & 406 & 154 & & \\
\hline & & & & & & & wave7 & 848 & 1.011 & 759 & 605 & \\
\hline & & & & & & & wave8 & 1.064 & 1.226 & 974 & 820 & 216 \\
\hline & & & & & & & $\mathrm{G}$ & & & & & \\
\hline & & & & & & & wave4 & 0,0043 & & & & \\
\hline & & & & & & & wave5 & 0,0147 & 0,0104 & & & \\
\hline & & & & & & & wave6 & 0,0221 & 0,0178 & 0,0074 & & \\
\hline & & & & & & & wave7 & 0,0200 & 0,0157 & 0,0053 & $-0,0021$ & \\
\hline & & & & & & & wave8 & 0,0249 & 0,0206 & 0,0102 & 0,0028 & 0,0049 \\
\hline
\end{tabular}

Note: $\mathbf{C I}=C\left(h_{i t} \mid y_{i t}\right) ; \mathbf{h}=H_{t} ; \mathbf{y}=Y_{t} ; \mathbf{G}=G\left(y_{i t}\right) ; \mathbf{C I t}-\mathbf{C I} 1=C\left(h_{i t} \mid y_{i t}\right)-C\left(h_{i 1} \mid y_{i 1}\right)$; ineq_in: equation (2.20); elas_in: equation (2.14); past_in: equation (2.24); ineq_ot: equation (2.21); elas_ot: equation (2.15); past_ot: equation (2.25); ineq: sum of all ineq_-terms; elas: sum of all elas_terms; past: sum of all past_terms; shaded: statistically significantly different from zero at $5 \%$ level. 
Appendix Table 7: detailed information for France

\begin{tabular}{|c|c|c|c|c|c|c|c|c|c|c|c|c|c|c|c|c|}
\hline & wave1 & wave2 & wave3 & wave4 & wave5 & wave6 & wave7 & wave8 & PAIRWIS & TESTS O & DIFFERE & & & & & \\
\hline $\mathrm{Cl}$ & 0,0081 & 0,0082 & 0,0083 & 0,0086 & 0,0087 & 0,0089 & 0,0094 & 0,0102 & $\mathrm{Cl}$ & wave1 & wave2 & wave3 & wave4 & wave5 & wave6 & wave7 \\
\hline h & 0,8745 & 0,8736 & 0,8719 & 0,8714 & 0,8703 & 0,8689 & 0,8680 & 0,8678 & \begin{tabular}{|l|} 
wave2 \\
\end{tabular} & 0,0000 & & & & & & \\
\hline y & 14177 & 13902 & 13872 & 14442 & 14749 & 15061 & 15300 & 15889 & wave3 & 0,0002 & 0,0002 & & & & & \\
\hline G & 0,3335 & 0,2896 & 0,2811 & 0,2815 & 0,2783 & 0,2874 & 0,2809 & 0,2712 & wave4 & 0,0005 & 0,0005 & 0,0003 & & & & \\
\hline $\mathrm{N}$ & 6836 & 6836 & 6836 & 6836 & 6836 & 6836 & 6836 & 6836 & wave5 & 0,0005 & 0,0005 & 0,0003 & 0,0001 & & & \\
\hline $\mathrm{Clt}-\mathrm{Cl} 1$ & & 0,00001 & 0,00019 & 0,00047 & 0,00052 & 0,00072 & 0,00123 & 0,00206 & wave6 & 0,0007 & 0,0007 & 0,0005 & 0,0002 & 0,0002 & & \\
\hline ineq_in & & $-0,00010$ & $-0,00028$ & $-0,00017$ & $-0,00023$ & $-0,00035$ & $-0,00025$ & $-0,00040$ & wave7 & 0,0012 & 0,0012 & 0,0010 & 0,0008 & 0,0007 & 0,0005 & \\
\hline elas_in & & $-0,00007$ & $-0,00008$ & 0,00006 & 0,00014 & 0,00021 & 0,00026 & 0,00038 & wave8 & 0,0021 & 0,0020 & 0,0019 & 0,0016 & 0,0015 & 0,0013 & 0,0008 \\
\hline past_in & & 0,00002 & 0,00004 & 0,00005 & 0,00007 & 0,00009 & 0,00010 & 0,00012 & $\mathrm{~h}$ & & & & & & & \\
\hline ineq_ot & & 0,00028 & 0,00068 & 0,00066 & 0,00065 & 0,00094 & 0,00120 & 0,00197 & \begin{tabular}{|l|} 
wave2 \\
\end{tabular} & $-0,0008$ & & & & & & \\
\hline elas_ot & & 0,00000 & 0,00000 & 0,00000 & 0,00000 & 0,00000 & 0,00000 & 0,00000 & wave3 & $-0,0025$ & $-0,0017$ & & & & & \\
\hline past_ot & & $-0,00012$ & $-0,00017$ & $-0,00013$ & $-0,00011$ & $-0,00017$ & $-0,00009$ & $-0,00001$ & wave4 & $-0,0031$ & $-0,0022$ & $-0,0005$ & & & & \\
\hline ineq & & 0,00018 & 0,00040 & 0,00048 & 0,00042 & 0,00059 & 0,00095 & 0,00157 & wave5 & $-0,0041$ & $-0,0033$ & $-0,0016$ & $-0,0011$ & & & \\
\hline elas & & $-0,00007$ & $-0,00008$ & 0,00007 & 0,00014 & 0,00021 & 0,00026 & 0,00038 & wave6 & $-0,0056$ & $-0,0048$ & $-0,0031$ & $-0,0025$ & $-0,0015$ & & \\
\hline past & & $-0,00010$ & $-0,00013$ & $-0,00008$ & $-0,00004$ & $-0,00009$ & 0,00001 & 0,00010 & wave7 & $-0,0065$ & $-0,0056$ & $-0,0039$ & $-0,0034$ & $-0,0023$ & $-0,0009$ & \\
\hline & & & & & & & & & wave8 & $-0,0067$ & $-0,0059$ & $-0,0042$ & $-0,0036$ & $-0,0026$ & $-0,0011$ & $-0,0002$ \\
\hline & & & & & & & & & $\begin{array}{l}y \\
\end{array}$ & & & & & & & \\
\hline & & & & & & & & & wave2 & -275 & & & & & & \\
\hline & & & & & & & & & wave3 & -305 & -30 & & & & & \\
\hline & & & & & & & & & wave4 & 265 & 540 & 570 & & & & \\
\hline & & & & & & & & & wave5 & 572 & 847 & 877 & 307 & & & \\
\hline & & & & & & & & & wave6 & 884 & 1159 & 1189 & 619 & 312 & & \\
\hline & & & & & & & & & wave7 & 1123 & 1398 & 1427 & 858 & 551 & 239 & \\
\hline & & & & & & & & & wave8 & 1712 & 1988 & 2017 & 1447 & 1140 & 828 & 590 \\
\hline & & & & & & & & & G & & & & & & & \\
\hline & & & & & & & & & \begin{tabular}{|l|} 
wave2 \\
\end{tabular} & $-0,0439$ & & & & & & \\
\hline & & & & & & & & & wave3 & $-0,0524$ & $-0,0085$ & & & & & \\
\hline & & & & & & & & & wave4 & $-0,0520$ & $-0,0081$ & 0,0004 & & & & \\
\hline & & & & & & & & & wave5 & $-0,0552$ & $-0,0113$ & $-0,0028$ & $-0,0032$ & & & \\
\hline & & & & & & & & & wave6 & $-0,0461$ & $-0,0022$ & 0,0063 & 0,0059 & 0,0091 & & \\
\hline & & & & & & & & & wave7 & $-0,0525$ & $-0,0086$ & $-0,0002$ & $-0,0006$ & 0,0027 & $-0,0065$ & \\
\hline & & & & & & & & & wave8 & $-0,0623$ & $-0,0184$ & $-0,0099$ & $-0,0103$ & $-0,0071$ & $-0,0162$ & $-0,0098$ \\
\hline
\end{tabular}

Note: $\mathbf{C I}=C\left(h_{i t} \mid y_{i t}\right) ; \mathbf{h}=H_{t} ; \mathbf{y}=Y_{t} ; \mathbf{G}=G\left(y_{i t}\right) ; \mathbf{C I t}-\mathbf{C I 1}=C\left(h_{i t} \mid y_{i t}\right)-C\left(h_{i \mid} \mid y_{i 1}\right) ;$ ineq_in: equation (2.20); elas_in: equation (2.14); past_in: equation (2.24); ineq_ot: equation (2.21); elas_ot: equation (2.15); past_ot: equation (2.25); ineq: sum of all ineq_-terms; elas: sum of all elas_-terms; past: sum of all past_terms; shaded: statistically significantly different from zero at $5 \%$ level.

\section{Appendix Table 8: detailed information for Germany}

\begin{tabular}{|c|c|c|c|c|c|c|c|c|c|c|c|c|c|c|c|c|}
\hline & wave1 & wave2 & wave3 & wave4 & wave5 & wave6 & wave7 & wave8 & \multicolumn{8}{|c|}{ PAIRWISE TESTS ON DIFFERENCE } \\
\hline $\mathrm{Cl}$ & 0,0088 & 0,0083 & 0,0080 & 0,0080 & 0,0079 & 0,0076 & 0,0086 & 0,0091 & $\mathrm{Cl}$ & wave1 & wave2 & wave3 & wave4 & wave5 & wave6 & wave7 \\
\hline h & 0,8439 & 0,8405 & 0,8388 & 0,8374 & 0,8352 & 0,8338 & 0,8327 & 0,8294 & wave2 & $-0,00046$ & & & & & & \\
\hline y & 15431 & 14637 & 15077 & 15482 & 15475 & 16257 & 17229 & 16819 & wave3 & $-0,00082$ & $-0,0004$ & & & & & \\
\hline G & 0,2832 & 0,2697 & 0,2611 & 0,2501 & 0,2506 & 0,2549 & 0,2544 & 0,2525 & wave4 & $-0,0008$ & $-0,0004$ & 0,0000 & & & & \\
\hline $\mathrm{N}$ & 7520 & 7520 & 7520 & 7520 & 7520 & 7520 & 7520 & 7520 & wave5 & $-0,0009$ & $-0,0004$ & $-0,0001$ & $-0,0001$ & & & \\
\hline Clt-Cl1 & & $-0,00046$ & $-0,00082$ & $-0,00083$ & $-0,00090$ & $-0,00119$ & $-0,00020$ & 0,00029 & wave6 & $-0,0012$ & $-0,0007$ & $-0,0004$ & $-0,0004$ & $-0,0003$ & & \\
\hline ineq_in & & $-0,00030$ & $-0,00062$ & $-0,00100$ & $-0,00101$ & $-0,00099$ & $-0,00108$ & $-0,00113$ & wave7 & $-0,0002$ & 0,0003 & 0,0006 & 0,0006 & 0,0007 & 0,0010 & \\
\hline elas_in & & $-0,00011$ & $-0,00005$ & 0,00001 & 0,00001 & 0,00009 & 0,00018 & 0,00015 & wave8 & 0,0003 & 0,0007 & 0,0011 & 0,0011 & 0,0012 & 0,0015 & 0,0005 \\
\hline past_in & & 0,00002 & 0,00005 & 0,00007 & 0,00009 & 0,00012 & 0,00014 & 0,00017 & h & & & & & & & \\
\hline ineq ot & & $\begin{array}{l}-0,00007 \\
-\end{array}$ & $\begin{array}{l}, 0,00024 \\
-0,000\end{array}$ & 0,00005 & 0,00001 & $\begin{array}{c}, 0,00041 \\
-0,0\end{array}$ & 0,00062 & $\begin{array}{l}0,00122 \\
\end{array}$ & \begin{tabular}{|l|} 
wave2 \\
\end{tabular} & $-0,0035$ & & & & & & \\
\hline elas ot & & 0,00000 & 0,00000 & 0,00000 & 0,00000 & 0,00000 & 0,00000 & 0,00000 & wave3 & $-0,0051$ & $-0,0016$ & & & & & \\
\hline past ot & & $-0,00001$ & 0,00004 & 0,00004 & 0,00000 & $-0,00001$ & $-0,00006$ & $-0,00012$ & wave4 & $-0,0065$ & $-0,0030$ & $-0,0014$ & & & & \\
\hline ineq & & $-0,00037$ & $-0,00086$ & $-0,00095$ & $-0,00099$ & $-0,00140$ & $-0,00046$ & 0,00009 & wave5 & $-0,0087$ & $-0,0052$ & $-0,0036$ & $-0,0022$ & & & \\
\hline elas & & $-0,00011$ & $-0,00005$ & 0,00001 & 0,00001 & 0,00009 & 0,00018 & 0,00014 & wave6 & $-0,0101$ & $-0,0067$ & $-0,0050$ & $-0,0036$ & $-0,0014$ & & \\
\hline past & & 0,00002 & 0,00009 & 0,00011 & 0,00009 & 0,00011 & 0,00009 & 0,00005 & wave7 & $-0,0112$ & $-0,0077$ & $-0,0061$ & $-0,0047$ & $-0,0025$ & $-0,0011$ & \\
\hline & & & & & & & & & wave8 & $-0,0145$ & $-0,0110$ & $-0,0094$ & $-0,0080$ & $-0,0058$ & $-0,0044$ & $-0,0033$ \\
\hline & & & & & & & & & \begin{tabular}{|l|l}
$y$ \\
\end{tabular} & & & & & & & \\
\hline & & & & & & & & & wave2 & -794 & & & & & & \\
\hline & & & & & & & & & wave3 & -354 & 440 & & & & & \\
\hline & & & & & & & & & wave4 & 51 & 845 & 405 & & & & \\
\hline & & & & & & & & & $\begin{array}{l}\text { wave5 } \\
\text { la }\end{array}$ & 44 & 838 & 398 & -7 & & & \\
\hline & & & & & & & & & wave6 & 826 & 1620 & 1180 & 775 & 782 & & \\
\hline & & & & & & & & & wave7 & 1797 & 2591 & 2152 & 1746 & 1753 & 971 & \\
\hline & & & & & & & & & wave8 & 1388 & 2182 & 1742 & 1337 & 1344 & 562 & -409 \\
\hline & & & & & & & & & $\mathrm{G}$ & & & & & & & \\
\hline & & & & & & & & & \begin{tabular}{|l|} 
wave2 \\
\end{tabular} & $-0,0134$ & & & & & & \\
\hline & & & & & & & & & wave3 & $-0,0220$ & $-0,0086$ & & & & & \\
\hline & & & & & & & & & wave4 & $-0,0331$ & $-0,0197$ & $-0,0111$ & & & & \\
\hline & & & & & & & & & $\begin{array}{l}\text { wave5 } \\
\text { laves }\end{array}$ & $-0,0326$ & $-0,0191$ & $-0,0105$ & 0,0005 & & & \\
\hline & & & & & & & & & $\begin{array}{l}\text { wave6 } \\
\text { was }\end{array}$ & $-0,0283$ & $-0,0148$ & $-0,0062$ & 0,0048 & 0,0043 & & \\
\hline & & & & & & & & & wave7 & $-0,0288$ & $-0,0154$ & $-0,0068$ & 0,0043 & 0,0038 & $-0,0005$ & \\
\hline & & & & & & & & & wave8 & $\begin{array}{r}-0,0307 \\
\end{array}$ & $-0,0173$ & $-0,0087$ & 0,0024 & 0,0019 & $-0,0024$ & $-0,0019$ \\
\hline
\end{tabular}

Note: $\mathbf{C I}=C\left(h_{i t} \mid y_{i t}\right) ; \mathbf{h}=H_{t} ; \mathbf{y}=Y_{t} ; \mathbf{G}=G\left(y_{i t}\right) ; \mathbf{C I t}-\mathbf{C I I}=C\left(h_{i t} \mid y_{i t}\right)-C\left(h_{i 1} \mid y_{i 1}\right) ;$ ineq_in: equation (2.20); elas_in: equation (2.14);

past_in: equation (2.24); ineq_ot: equation (2.21); elas_ot: equation (2.15); past_ot: equation (2.25); ineq: sum of all ineq_-terms; elas: sum of all elas_-terms; past: sum of all past_terms; shaded: statistically significantly different from zero at $5 \%$ level. 
Appendix Table 9: detailed information for Greece

\begin{tabular}{|c|c|c|c|c|c|c|c|c|c|c|c|c|c|c|c|c|}
\hline & wave1 & wave2 & wave3 & wave4 & wave5 & wave6 & wave7 & wave8 & \multicolumn{8}{|c|}{ PAIRWISE TESTS ON DIFFERENCE } \\
\hline $\mathrm{Cl}$ & 0,0140 & 0,0145 & 0,0133 & 0,0156 & 0,0163 & 0,0160 & 0,0159 & 0,0166 & $\mathrm{Cl}$ & wave1 & wave2 & wave3 & wave4 & wave5 & wave6 & wave7 \\
\hline h & 0,9092 & 0,9078 & 0,9057 & 0,9037 & 0,9023 & 0,9012 & 0,8989 & 0,8962 & wave2 & 0,00056 & & & & & & \\
\hline y & 6817 & 7102 & 7322 & 7585 & 8061 & 8691 & 8752 & 8426 & wave3 & $-0,00069$ & $-0,00124$ & & & & & \\
\hline G & 0,3723 & 0,3537 & 0,3455 & 0,3548 & 0,3544 & 0,3504 & 0,3387 & 0,3337 & wave4 & 0,00168 & 0,00112 & 0,00236 & & & & \\
\hline $\mathrm{N}$ & 6134 & 6134 & 6134 & 6134 & 6134 & 6134 & 6134 & 6134 & wave5 & 0,00229 & 0,00173 & 0,00298 & 0,00061 & & & \\
\hline Clt-Cl1 & & 0,00056 & $-0,00069$ & 0,00168 & 0,00229 & 0,00206 & 0,00197 & 0,00266 & wave6 & 0,00206 & 0,00150 & 0,00275 & 0,00039 & $-0,00023$ & & \\
\hline ineq_in & & $-0,00019$ & $-0,00024$ & 0,00000 & 0,00004 & 0,00006 & $-0,00002$ & $-0,00024$ & wave7 & 0,00197 & 0,00141 & 0,00266 & 0,00029 & $-0,00032$ & $-0,00009$ & \\
\hline elas_in & & 0,00010 & 0,00016 & 0,00023 & 0,00029 & 0,00027 & 0,00026 & 0,00030 & wave8 & 0,00266 & 0,00211 & 0,00335 & 0,00099 & 0,00037 & 0,00060 & 0,00069 \\
\hline past_in & & 0,00002 & 0,00004 & 0,00007 & 0,00009 & 0,00011 & 0,00013 & 0,00015 & \begin{tabular}{|l}
$\mathrm{h}$ \\
\end{tabular} & & & & & & & \\
\hline ineq_ot & & 0,00061 & $-0,00065$ & 0,00130 & 0,00175 & 0,00149 & 0,00123 & 0,00214 & \begin{tabular}{|l|} 
wave2 \\
\end{tabular} & $-0,00136$ & & & & & & \\
\hline elas_ot & & $-0,00001$ & $-0,00001$ & $-0,00001$ & $-0,00002$ & $-0,00003$ & $-0,00003$ & $-0,00003$ & wave3 & $-0,00347$ & $-0,00210$ & & & & & \\
\hline past_ot & & 0,00002 & 0,00001 & 0,00010 & 0,00015 & 0,00017 & 0,00039 & 0,00034 & wave4 & $-0,00545$ & $-0,00409$ & $-0,00199$ & & & & \\
\hline ineq & & 0,0004 & $-0,0009$ & 0,0013 & 0,0018 & 0,0015 & 0,0012 & 0,0019 & wave5 & $-0,00690$ & $-0,00554$ & $-0,00343$ & $-0,00144$ & & & \\
\hline elas & & 0,0001 & 0,0002 & 0,0002 & 0,0003 & 0,0002 & 0,0002 & 0,0003 & wave6 & $-0,00793$ & $-0,00657$ & $-0,00447$ & $-0,00248$ & $-0,00103$ & & \\
\hline past & & 0,0000 & 0,0001 & 0,0002 & 0,0002 & 0,0003 & 0,0005 & 0,0005 & wave7 & $-0,01024$ & $-0,00888$ & $-0,00677$ & $-0,00478$ & $-0,00334$ & $-0,00231$ & \\
\hline & & & & & & & & & wave8 & $-0,01291$ & $-0,01155$ & $-0,00944$ & $-0,00745$ & $-0,00601$ & $-0,00498$ & $-0,00267$ \\
\hline & & & & & & & & & $\begin{array}{l}y \\
\end{array}$ & & & & & & & \\
\hline & & & & & & & & & wave2 & 285 & & & & & & \\
\hline & & & & & & & & & wave3 & 505 & 220 & & & & & \\
\hline & & & & & & & & & wave4 & 768 & 483 & 263 & & & & \\
\hline & & & & & & & & & wave5 & 1244 & 959 & 739 & 476 & & & \\
\hline & & & & & & & & & wave6 & 1874 & 1589 & 1369 & 1106 & 630 & & \\
\hline & & & & & & & & & $\begin{array}{l}\text { wave7 } \\
\text { wan }\end{array}$ & 1935 & 1650 & 1430 & 1167 & 691 & 61 & \\
\hline & & & & & & & & & wave8 & 1609 & 1323 & 1104 & 841 & 365 & -265 & -326 \\
\hline & & & & & & & & & G & & & & & & & \\
\hline & & & & & & & & & \begin{tabular}{|l|} 
wave2 \\
\end{tabular} & $-0,01855$ & & & & & & \\
\hline & & & & & & & & & wave3 & $-0,02684$ & $-0,00829$ & & & & & \\
\hline & & & & & & & & & wave4 & $-0,01747$ & 0,00108 & 0,00937 & & & & \\
\hline & & & & & & & & & wave5 & $-0,01785$ & 0,00070 & 0,00899 & $-0,00038$ & & & \\
\hline & & & & & & & & & wave6 & $-0,02191$ & $-0,00336$ & 0,00492 & $-0,00445$ & $-0,00406$ & & \\
\hline & & & & & & & & & wave7 & $-0,03360$ & $-0,01505$ & $-0,00677$ & $-0,01613$ & $-0,01575$ & $-0,01169$ & \\
\hline & & & & & & & & & wave8 & $-0,03861$ & $-0,02006$ & $-0,01178$ & $-0,02115$ & $-0,02076$ & $-0,01670$ & $-0,00501$ \\
\hline
\end{tabular}

Note: $\mathbf{C I}=C\left(h_{i t} \mid y_{i t}\right) ; \mathbf{h}=H_{t} ; \mathbf{y}=Y_{t} ; \mathbf{G}=G\left(y_{i t}\right) ; \mathbf{C I t}-\mathbf{C I} 1=C\left(h_{i t} \mid y_{i t}\right)-C\left(h_{i 1} \mid y_{i 1}\right) ;$ ineq_in: equation (2.20); elas_in: equation (2.14); past_in: equation (2.24); ineq_ot: equation (2.21); elas_ot: equation (2.15); past_ot: equation (2.25); ineq: sum of all ineq_-terms; elas: sum of all elas_-terms; past: sum of all past_terms; shaded: statistically significantly different from zero at $5 \%$ level.

Appendix Table 10: detailed information for Ireland

\begin{tabular}{|c|c|c|c|c|c|c|c|c|c|c|c|c|c|c|c|c|}
\hline & wave1 & wave2 & wave3 & wave4 & wave5 & wave6 & wave7 & wave8 & \multicolumn{8}{|c|}{ PAIRWISE TESTS ON DIFFERENCE } \\
\hline$\overline{\mathrm{Cl}}$ & 0,0073 & 0,0075 & 0,0079 & 0,0082 & 0,0087 & 0,0092 & 0,0096 & 0,0099 & $\mathrm{Cl}$ & wave1 & wave2 & wave3 & wave4 & wave5 & wave6 & wave7 \\
\hline h & 0,9263 & 0,9262 & 0,9251 & 0,9260 & 0,9251 & 0,9246 & 0,9242 & 0,9246 & wave2 & $\overline{0,0002}$ & & & & & & \\
\hline y & 10089 & 10712 & 10526 & 11450 & 11384 & 11882 & 11873 & 12509 & wave3 & 0,0006 & 0,0004 & & & & & \\
\hline G & 0,3168 & 0,3258 & 0,3269 & 0,3179 & 0,3150 & 0,3296 & 0,3149 & 0,3101 & wave4 & 0,0008 & 0,0007 & 0,0002 & & & & \\
\hline $\mathrm{N}$ & 2872 & 2872 & 2872 & 2872 & 2872 & 2872 & 2872 & 2872 & wave5 & 0,0014 & 0,0012 & 0,0008 & 0,0006 & & & \\
\hline CIt-Cl1 & & 0,00016 & 0,00061 & 0,00084 & 0,00139 & 0,00184 & 0,00231 & 0,00252 & wave6 & 0,0018 & 0,0017 & 0,0012 & 0,0010 & 0,0004 & & \\
\hline ineq_in & & $-0,00003$ & $-0,00007$ & $-0,00015$ & $-0,00010$ & $-0,00001$ & 0,00013 & 0,00017 & wave7 & 0,0023 & 0,0021 & 0,0017 & 0,0015 & 0,0009 & 0,0005 & \\
\hline elas_in & & 0,00000 & 0,00001 & $-0,00002$ & $-0,00002$ & $-0,00006$ & $-0,00006$ & $-0,00012$ & wave8 & 0,0025 & 0,0024 & 0,0019 & 0,0017 & 0,0011 & 0,0007 & 0,0002 \\
\hline past_in & & 0,00001 & 0,00001 & 0,00002 & 0,00003 & 0,00003 & 0,00004 & 0,00004 & $\mathrm{~h}$ & & & & & & & \\
\hline ineq_ot & & 0,00020 & 0,00070 & 0,00096 & 0,00145 & 0,00196 & 0,00228 & 0,00254 & wave2 & $-0,0001$ & & & & & & \\
\hline elas_ot & & 0,00000 & 0,00000 & 0,00000 & 0,00000 & 0,00000 & 0,00000 & 0,00000 & wave3 & $-0,0012$ & $-0,0012$ & & & & & \\
\hline past ot & & $-0,00001$ & $-0,00004$ & 0,00003 & 0,00003 & $-0,00008$ & $-0,00008$ & $-0,00010$ & wave4 & $-0,0003$ & $-0,0002$ & 0,0009 & & & & \\
\hline ineq & & 0,00016 & 0,00063 & 0,00081 & 0,00135 & 0,00194 & 0,00241 & 0,00271 & wave5 & $-0,0012$ & $-0,0012$ & 0,0000 & $-0,0009$ & & & \\
\hline elas & & 0,00000 & 0,00001 & $-0,00003$ & $-0,00002$ & $-0,00006$ & $-0,00006$ & $-0,00013$ & wave6 & $-0,0017$ & $-0,0017$ & $-0,0005$ & $-0,0014$ & $-0,0005$ & & \\
\hline past & & 0,00000 & $-0,00002$ & 0,00005 & 0,00006 & $-0,00005$ & $-0,00004$ & $-0,00006$ & wave7 & $-0,0021$ & $-0,0020$ & $-0,0009$ & $-0,0018$ & $-0,0009$ & $-0,0004$ & \\
\hline & & & & & & & & & wave8 & $-0,0017$ & $-0,0016$ & $-0,0005$ & $-0,0014$ & $-0,0005$ & 0,0000 & 0,0004 \\
\hline & & & & & & & & & $y$ & & & & & & & \\
\hline & & & & & & & & & wave2 & 622 & & & & & & \\
\hline & & & & & & & & & wave3 & 437 & -186 & & & & & \\
\hline & & & & & & & & & wave4 & 1361 & 738 & 924 & & & & \\
\hline & & & & & & & & & wave5 & 1294 & 672 & 858 & -66 & & & \\
\hline & & & & & & & & & wave6 & 1793 & 1170 & 1356 & 432 & 498 & & \\
\hline & & & & & & & & & wave7 & 1784 & 1161 & 1347 & 423 & 490 & -9 & \\
\hline & & & & & & & & & wave8 & 2419 & 1797 & 1983 & 1059 & 1125 & 627 & 636 \\
\hline & & & & & & & & & G & & & & & & & \\
\hline & & & & & & & & & wave2 & $\overline{0,0090}$ & & & & & & \\
\hline & & & & & & & & & wave3 & 0,0101 & 0,0011 & & & & & \\
\hline & & & & & & & & & wave4 & 0,0011 & $-0,0079$ & $-0,0090$ & & & & \\
\hline & & & & & & & & & wave5 & $-0,0017$ & $-0,0108$ & $-0,0119$ & $-0,0029$ & & & \\
\hline & & & & & & & & & wave6 & 0,0128 & 0,0038 & 0,0027 & 0,0117 & 0,0146 & & \\
\hline & & & & & & & & & wave7 & $-0,0019$ & $-0,0109$ & $-0,0120$ & $-0,0030$ & $-0,0001$ & $-0,0147$ & \\
\hline & & & & & & & & & wave8 & $-0,0067$ & $-0,0157$ & $-0,0168$ & $-0,0078$ & $-0,0049$ & $-0,0195$ & $-0,0048$ \\
\hline
\end{tabular}

Note: $\mathbf{C I}=C\left(h_{i t} \mid y_{i t}\right) ; \mathbf{h}=H_{t} ; \mathbf{y}=Y_{t} ; \mathbf{G}=G\left(y_{i t}\right) ; \mathbf{C I t}-\mathbf{C I 1}=C\left(h_{i t} \mid y_{i t}\right)-C\left(h_{i 1} \mid y_{i 1}\right) ;$ ineq_in: equation (2.20); elas_in: equation (2.14); past_in: equation (2.24); ineq_ot: equation (2.21); elas_ot: equation (2.15); past_ot: equation (2.25); ineq: sum of all ineq_-terms; elas: sum of all elas_terms; past: sum of all past_terms; shaded: statistically significantly different from zero at $5 \%$ level. 
Appendix Table 11: detailed information for Italy

\begin{tabular}{|c|c|c|c|c|c|c|c|c|c|c|c|c|c|c|c|c|}
\hline & wave1 & wave2 & wave3 & wave4 & wave5 & wave6 & wave7 & wave8 & \multicolumn{8}{|c|}{ PAIRWISE TESTS ON DIFFERENCE } \\
\hline $\mathrm{Cl}$ & 0,0053 & 0,0061 & 0,0056 & 0,0058 & 0,0066 & 0,0064 & 0,0064 & 0,0076 & $\mathrm{Cl}$ & wave1 & wave2 & wave3 & wave4 & wave5 & wave6 & wave7 \\
\hline h & 0,8791 & 0,8770 & 0,8751 & 0,8729 & 0,8717 & 0,8702 & 0,8675 & 0,8646 & wave2 & 0,00080 & & & & & & \\
\hline y & 10020 & 10174 & 10461 & 10336 & 11152 & 11873 & 11832 & 11534 & wave3 & 0,00027 & $-0,00053$ & & & & & \\
\hline G & 0,3331 & 0,3342 & 0,3264 & 0,3093 & 0,3072 & 0,3068 & 0,2933 & 0,2936 & wave4 & 0,00049 & $-0,00031$ & 0,00022 & & & & \\
\hline $\mathrm{N}$ & 9036 & 9036 & 9036 & 9036 & 9036 & 9036 & 9036 & 9036 & wave5 & 0,00127 & 0,00047 & 0,00100 & 0,00078 & & & \\
\hline Clt-Cl1 & & 0,00080 & 0,00027 & 0,00049 & 0,00127 & 0,00111 & 0,00115 & 0,00228 & wave6 & 0,00111 & 0,00031 & 0,00084 & 0,00062 & $-0,00016$ & & \\
\hline ineq_in & & $-0,00006$ & $-0,00019$ & $-0,00025$ & $-0,00043$ & $-0,00050$ & $-0,00068$ & $-0,00068$ & wave7 & 0,00115 & 0,00035 & 0,00088 & 0,00066 & $-0,00012$ & 0,00004 & \\
\hline elas_in & & 0,00005 & 0,00013 & 0,00010 & 0,00033 & 0,00050 & 0,00050 & 0,00043 & wave8 & 0,00228 & 0,00148 & 0,00201 & 0,00179 & 0,00101 & 0,00117 & 0,00113 \\
\hline past_in & & 0,00002 & 0,00003 & 0,00005 & 0,00006 & 0,00008 & 0,00010 & 0,00012 & \begin{tabular}{|l}
$\mathrm{h}$ \\
\end{tabular} & & & & & & & \\
\hline ineq_ot & & 0,00086 & 0,00042 & 0,00085 & 0,00147 & 0,00120 & 0,00146 & 0,00261 & \begin{tabular}{|l|} 
wave2 \\
\end{tabular} & $-0,00207$ & & & & & & \\
\hline elas_ot & & 0,00000 & 0,00000 & 0,00000 & 0,00000 & 0,00000 & 0,00000 & 0,00000 & wave3 & $-0,00401$ & $-0,00194$ & & & & & \\
\hline past_ot & & $-0,00006$ & $-0,00013$ & $-0,00025$ & $-0,00016$ & $-0,00018$ & $-0,00023$ & $-0,00020$ & wave4 & $-0,00622$ & $-0,00415$ & $-0,00221$ & & & & \\
\hline ineq & & 0,00080 & 0,00023 & 0,00059 & 0,00104 & 0,00071 & 0,00078 & 0,00193 & wave5 & $-0,00738$ & $-0,00531$ & $-0,00337$ & $-0,00116$ & & & \\
\hline elas & & 0,00005 & 0,00013 & 0,00010 & 0,00033 & 0,00051 & 0,00050 & 0,00043 & wave6 & $-0,00891$ & $-0,00684$ & $-0,00490$ & $-0,00269$ & $-0,00153$ & & \\
\hline past & & $-0,00005$ & $-0,00009$ & $-0,00020$ & $-0,00010$ & $-0,00010$ & $-0,00013$ & $-0,00009$ & wave7 & $-0,01161$ & $-0,00954$ & $-0,00760$ & $-0,00539$ & $-0,00423$ & $-0,00270$ & \\
\hline & & & & & & & & & wave8 & $-0,01449$ & $-0,01242$ & $-0,01048$ & $-0,00827$ & $-0,00711$ & $-0,00558$ & $-0,00288$ \\
\hline & & & & & & & & & $\begin{array}{l}y \\
\end{array}$ & & & & & & & \\
\hline & & & & & & & & & wave2 & 154 & & & & & & \\
\hline & & & & & & & & & wave3 & 442 & 288 & & & & & \\
\hline & & & & & & & & & wave4 & 317 & 162 & -125 & & & & \\
\hline & & & & & & & & & wave5 & 1132 & 978 & 690 & 815 & & & \\
\hline & & & & & & & & & wave6 & 1854 & 1699 & 1412 & 1537 & 721 & & \\
\hline & & & & & & & & & $\begin{array}{l}\text { wave7 } \\
\text { wan }\end{array}$ & 1812 & 1658 & 1371 & 1496 & 680 & -41 & \\
\hline & & & & & & & & & wave8 & 1514 & 1360 & 1072 & 1198 & 382 & -339 & -298 \\
\hline & & & & & & & & & G & & & & & & & \\
\hline & & & & & & & & & \begin{tabular}{|l|} 
wave2 \\
\end{tabular} & 0,00106 & & & & & & \\
\hline & & & & & & & & & wave3 & $-0,00673$ & $-0,00779$ & & & & & \\
\hline & & & & & & & & & wave4 & $-0,02385$ & $-0,02490$ & $-0,01712$ & & & & \\
\hline & & & & & & & & & wave5 & $-0,02591$ & $-0,02697$ & $-0,01918$ & $-0,00207$ & & & \\
\hline & & & & & & & & & wave6 & $-0,02634$ & $-0,02740$ & $-0,01961$ & $-0,00249$ & $-0,00043$ & & \\
\hline & & & & & & & & & wave7 & $-0,03978$ & $-0,04084$ & $-0,03305$ & $-0,01593$ & $-0,01387$ & $-0,01344$ & \\
\hline & & & & & & & & & wave8 & $-0,03948$ & $-0,04054$ & $-0,03275$ & $-0,01563$ & $-0,01357$ & $-0,01314$ & 0,00030 \\
\hline
\end{tabular}

Note: $\mathbf{C I}=C\left(h_{i t} \mid y_{i t}\right) ; \mathbf{h}=H_{t} ; \mathbf{y}=Y_{t} ; \mathbf{G}=G\left(y_{i t}\right) ; \mathbf{C I t}-\mathbf{C I} 1=C\left(h_{i t} \mid y_{i t}\right)-C\left(h_{i 1} \mid y_{i 1}\right) ;$ ineq_in: equation (2.20); elas_in: equation (2.14); past_in: equation (2.24); ineq_ot: equation (2.21); elas_ot: equation (2.15); past_ot: equation (2.25); ineq: sum of all ineq_-terms; elas: sum of all elas_-terms; past: sum of all past_terms; shaded: statistically significantly different from zero at $5 \%$ level.

Appendix Table 12: detailed information for the Netherlands

\begin{tabular}{|c|c|c|c|c|c|c|c|c|c|c|c|c|c|c|c|c|}
\hline & wave1 & wave2 & wave3 & wave4 & wave5 & wave6 & wave7 & wave8 & \multicolumn{8}{|c|}{ PAIRWISE TESTS ON DIFFERENCE } \\
\hline$\overline{\mathrm{Cl}}$ & 0,0041 & 0,0036 & 0,0040 & 0,0038 & 0,0039 & 0,0045 & 0,0039 & 0,0043 & $\mathrm{Cl}$ & wave1 & wave2 & wave3 & wave4 & wave5 & wave6 & wave7 \\
\hline h & 0,9056 & 0,9044 & 0,9039 & 0,9040 & 0,9034 & 0,9027 & 0,9015 & 0,9008 & wave2 & $-0,0005$ & & & & & & \\
\hline y & 13000 & 13209 & 13730 & 14419 & 14808 & 15157 & 14617 & 15081 & wave3 & $-0,0002$ & 0,0003 & & & & & \\
\hline G & 0,2550 & 0,2819 & 0,2890 & 0,2491 & 0,2466 & 0,2487 & 0,2293 & 0,2399 & wave4 & $-0,0003$ & 0,0002 & $-0,0001$ & & & & \\
\hline $\mathrm{N}$ & 4556 & 4556 & 4556 & 4556 & 4556 & 4556 & 4556 & 4556 & wave5 & $-0,0002$ & 0,0003 & 0,0000 & 0,0001 & & & \\
\hline Clt-Cl1 & & $-0,00052$ & $-0,00019$ & $-0,00031$ & $-0,00023$ & 0,00035 & $-0,00023$ & 0,00016 & wave6 & 0,0003 & 0,0009 & 0,0005 & 0,0007 & 0,0006 & & \\
\hline ineq_in & & $-0,00004$ & 0,00004 & $-0,00028$ & $-0,00029$ & $-0,00030$ & $-0,00041$ & $-0,00033$ & wave7 & $-0,0002$ & 0,0003 & 0,0000 & 0,0001 & 0,0000 & $-0,0006$ & \\
\hline elas_in & & 0,00003 & 0,00010 & 0,00018 & 0,00023 & 0,00027 & 0,00021 & 0,00026 & wave8 & 0,0002 & 0,0007 & 0,0004 & 0,0005 & 0,0004 & $-0,0002$ & 0,0004 \\
\hline past_in & & 0,00000 & 0,00001 & 0,00001 & 0,00002 & 0,00002 & 0,00002 & 0,00003 & $\mathrm{~h}$ & & & & & & & \\
\hline ineq_ot & & $-0,00043$ & $-0,00020$ & $-0,00003$ & 0,00003 & 0,00061 & 0,00016 & 0,00039 & wave2 & $-0,0011$ & & & & & & \\
\hline elas_ot & & 0,00000 & 0,00000 & 0,00000 & 0,00000 & 0,00000 & 0,00000 & 0,00000 & wave3 & $-0,0017$ & $-0,0005$ & & & & & \\
\hline past ot & & $-0,00009$ & $-0,00014$ & $-0,00019$ & $-0,00021$ & $-0,00024$ & $-0,00022$ & $-0,00018$ & wave4 & $-0,0016$ & $-0,0004$ & 0,0001 & & & & \\
\hline ineq & & $-0,00046$ & $-0,00016$ & $-0,00031$ & $-0,00027$ & 0,00030 & $-0,00024$ & 0,00006 & wave5 & $-0,0022$ & $-0,0010$ & $-0,0005$ & $-0,0006$ & & & \\
\hline elas & & 0,00003 & 0,00010 & 0,00018 & 0,00023 & 0,00026 & 0,00021 & 0,00026 & wave6 & $-0,0029$ & $-0,0017$ & $-0,0012$ & $-0,0013$ & $-0,0007$ & & \\
\hline past & & $-0,00009$ & $-0,00013$ & $-0,00018$ & $-0,00020$ & $-0,00022$ & $-0,00019$ & $-0,00015$ & wave7 & $-0,0041$ & $-0,0029$ & $-0,0024$ & $-0,0025$ & $-0,0019$ & $-0,0012$ & \\
\hline & & & & & & & & & wave8 & $-0,0047$ & $-0,0036$ & $-0,0031$ & $-0,0032$ & $-0,0026$ & $-0,0019$ & $-0,0007$ \\
\hline & & & & & & & & & $y$ & & & & & & & \\
\hline & & & & & & & & & wave2 & 209 & & & & & & \\
\hline & & & & & & & & & wave3 & 731 & 522 & & & & & \\
\hline & & & & & & & & & wave4 & 1419 & 1210 & 689 & & & & \\
\hline & & & & & & & & & wave5 & 1808 & 1600 & 1078 & 389 & & & \\
\hline & & & & & & & & & wave6 & 2157 & 1948 & 1426 & 738 & 348 & & \\
\hline & & & & & & & & & wave7 & 1618 & 1409 & 887 & 199 & -191 & -539 & \\
\hline & & & & & & & & & wave8 & 2082 & 1873 & 1351 & 663 & 273 & -75 & 464 \\
\hline & & & & & & & & & G & & & & & & & \\
\hline & & & & & & & & & wave2 & 0,0270 & & & & & & \\
\hline & & & & & & & & & wave3 & 0,0341 & 0,0071 & & & & & \\
\hline & & & & & & & & & wave4 & $-0,0059$ & $-0,0329$ & $-0,0400$ & & & & \\
\hline & & & & & & & & & wave5 & $-0,0084$ & $-0,0354$ & $-0,0425$ & $-0,0025$ & & & \\
\hline & & & & & & & & & wave6 & $-0,0063$ & $-0,0333$ & $-0,0404$ & $-0,0004$ & 0,0021 & & \\
\hline & & & & & & & & & wave7 & $-0,0256$ & $-0,0526$ & $-0,0597$ & $-0,0197$ & $-0,0173$ & $-0,0194$ & \\
\hline & & & & & & & & & wave8 & $-0,0150$ & $-0,0420$ & $-0,0491$ & $-0,0091$ & $-0,0067$ & $-0,0088$ & 0,0106 \\
\hline
\end{tabular}

Note: $\mathbf{C I}=C\left(h_{i t} \mid y_{i t}\right) ; \mathbf{h}=H_{t} ; \mathbf{y}=Y_{t} ; \mathbf{G}=G\left(y_{i t}\right) ; \mathbf{C I t}-\mathbf{C I 1}=C\left(h_{i t} \mid y_{i t}\right)-C\left(h_{i 1} \mid y_{i 1}\right) ;$ ineq_in: equation (2.20); elas_in: equation (2.14); past_in: equation (2.24); ineq_ot: equation (2.21); elas_ot: equation (2.15); past_ot: equation (2.25); ineq: sum of all ineq_-terms; elas: sum of all elas_terms; past: sum of all past_terms; shaded: statistically significantly different from zero at $5 \%$ level. 
Appendix Table 13: detailed information for Portugal

\begin{tabular}{|c|c|c|c|c|c|c|c|c|c|c|c|c|c|c|c|c|}
\hline & wave1 & wave2 & wave3 & wave4 & wave5 & wave6 & wave7 & wave8 & \multicolumn{8}{|c|}{ PAIRWISE TESTS ON DIFFERENCE } \\
\hline $\mathrm{Cl}$ & 0,0201 & 0,0197 & 0,0199 & 0,0207 & 0,0215 & 0,0223 & 0,0229 & 0,0237 & $\mathrm{Cl}$ & wave1 & wave2 & wave3 & wave4 & wave5 & wave6 & wave7 \\
\hline h & 0,8370 & 0,8345 & 0,8328 & 0,8306 & 0,8291 & 0,8281 & 0,8264 & 0,8245 & wave2 & $-0,0004$ & & & & & & \\
\hline y & 7183 & 7210 & 7554 & 7773 & 8242 & 8654 & 9088 & 9527 & wave3 & $-0,0002$ & 0,0002 & & & & & \\
\hline $\mathrm{G}$ & 0,3669 & 0,3556 & 0,3502 & 0,3498 & 0,3575 & 0,3506 & 0,3534 & 0,3602 & wave4 & 0,0006 & 0,0010 & 0,0008 & & & & \\
\hline $\mathrm{N}$ & 7097 & 7097 & 7097 & 7097 & 7097 & 7097 & 7097 & 7097 & wave5 & 0,0014 & 0,0019 & 0,0016 & 0,0008 & & & \\
\hline Clt-Cl1 & & $-0,00045$ & $-0,00022$ & 0,00058 & 0,00143 & 0,00220 & 0,00282 & 0,00355 & wave6 & 0,0022 & 0,0026 & 0,0024 & 0,0016 & 0,0008 & & \\
\hline ineq_in & & $-0,00035$ & $-0,00067$ & $-0,00074$ & $-0,00064$ & $-0,00087$ & $-0,00081$ & $-0,00093$ & wave7 & 0,0028 & 0,0033 & 0,0030 & 0,0022 & 0,0014 & 0,0006 & \\
\hline elas_in & & 0,00002 & 0,00030 & 0,00047 & 0,00079 & 0,00104 & 0,00127 & 0,00146 & wave8 & 0,0036 & 0,0040 & 0,0038 & 0,0030 & 0,0021 & 0,0014 & 0,0007 \\
\hline past_in & & 0,00005 & 0,00010 & 0,00015 & 0,00020 & 0,00024 & 0,00030 & 0,00035 & $\mathrm{~h}$ & & & & & & & \\
\hline ineq_ot & & $-0,00019$ & $-0,00006$ & 0,00068 & 0,00103 & 0,00190 & 0,00203 & 0,00249 & wave2 & $-0,0025$ & & & & & & \\
\hline elas_ot & & 0,00000 & $-0,00001$ & $-0,00002$ & $-0,00003$ & $-0,00004$ & $-0,00006$ & $-0,00007$ & wave3 & $-0,0042$ & $-0,0017$ & & & & & \\
\hline past_ot & & 0,00003 & 0,00012 & 0,00004 & 0,00008 & $-0,00006$ & 0,00009 & 0,00026 & wave4 & $-0,0064$ & $-0,0039$ & $-0,0022$ & & & & \\
\hline ineq & & $-0,00055$ & $-0,00073$ & $-0,00006$ & 0,00039 & 0,00102 & 0,00122 & 0,00156 & wave5 & $-0,0079$ & $-0,0054$ & $-0,0037$ & $-0,0015$ & & & \\
\hline elas & & 0,00002 & 0,00029 & 0,00045 & 0,00076 & 0,00099 & 0,00121 & 0,00139 & wave6 & $-0,0089$ & $-0,0064$ & $-0,0047$ & $-0,0026$ & $-0,0011$ & & \\
\hline past & & 0,00008 & 0,00022 & 0,00019 & 0,00028 & 0,00018 & 0,00039 & 0,00060 & wave7 & $-0,0106$ & $-0,0081$ & $-0,0064$ & $-0,0043$ & $-0,0028$ & $-0,0017$ & \\
\hline & & & & & & & & & wave8 & $-0,0125$ & $-0,0100$ & $-0,0083$ & $-0,0062$ & $-0,0047$ & $-0,0036$ & $-0,0019$ \\
\hline & & & & & & & & & \begin{tabular}{|l|}
$y$ \\
\end{tabular} & & & & & & & \\
\hline & & & & & & & & & wave2 & 27 & & & & & & \\
\hline & & & & & & & & & wave3 & 371 & 344 & & & & & \\
\hline & & & & & & & & & wave4 & 590 & 563 & 219 & & & & \\
\hline & & & & & & & & & wave5 & 1059 & 1032 & 688 & 469 & & & \\
\hline & & & & & & & & & wave6 & 1471 & 1444 & 1100 & 881 & 412 & & \\
\hline & & & & & & & & & wave7 & 1905 & 1879 & 1534 & 1316 & 846 & 435 & \\
\hline & & & & & & & & & wave8 & 2344 & 2317 & 1973 & 1754 & 1285 & 873 & 439 \\
\hline & & & & & & & & & G & & & & & & & \\
\hline & & & & & & & & & \begin{tabular}{|l|} 
wave2 \\
\end{tabular} & $-0,0113$ & & & & & & \\
\hline & & & & & & & & & Wave3 & $-0,0166$ & $-0,0053$ & & & & & \\
\hline & & & & & & & & & wave4 & $-0,0170$ & $-0,0058$ & $-0,0004$ & & & & \\
\hline & & & & & & & & & wave5 & $-0,0093$ & 0,0019 & 0,0073 & 0,0077 & & & \\
\hline & & & & & & & & & wave6 & $-0,0162$ & $-0,0049$ & 0,0004 & 0,0008 & $-0,0069$ & & \\
\hline & & & & & & & & & wave7 & $-0,0135$ & $-0,0022$ & 0,0031 & 0,0036 & $-0,0042$ & 0,0027 & \\
\hline & & & & & & & & & wave8 & $-0,0067$ & 0,0046 & 0,0100 & 0,0104 & 0,0027 & 0,0096 & 0,0068 \\
\hline
\end{tabular}

Note: $\mathbf{C I}=C\left(h_{i t} \mid y_{i t}\right) ; \mathbf{h}=H_{t} ; \mathbf{y}=Y_{t} ; \mathbf{G}=G\left(y_{i t}\right) ; \mathbf{C I t}-\mathbf{C I} 1=C\left(h_{i t} \mid y_{i t}\right)-C\left(h_{i 1} \mid y_{i 1}\right) ;$ ineq_in: equation (2.20); elas_in: equation (2.14); past_in: equation (2.24); ineq_ot: equation (2.21); elas_ot: equation (2.15); past_ot: equation (2.25); ineq: sum of all ineq_-terms; elas: sum of all elas_terms; past: sum of all past_terms; shaded: statistically significantly different from zero at $5 \%$ level.

\section{Appendix Table 14: detailed information for Spain}

\begin{tabular}{|c|c|c|c|c|c|c|c|c|c|c|c|c|c|c|c|c|}
\hline & wave1 & wave2 & wave3 & wave4 & wave5 & wave6 & wave7 & wave8 & PAIRWIS & TESTS OI & V DIFFERE & NCE & & & & \\
\hline $\mathrm{Cl}$ & 0,0094 & 0,0096 & 0,0094 & 0,0097 & 0,0100 & 0,0111 & 0,0122 & 0,0127 & $\mathrm{Cl}$ & wave1 & wave2 & wave3 & wave4 & wave5 & wave6 & wave7 \\
\hline h & 0,8829 & 0,8816 & 0,8803 & 0,8782 & 0,8769 & 0,8772 & 0,8760 & 0,8752 & \begin{tabular}{|l|} 
wave2 \\
\end{tabular} & 0,00013 & & & & & & \\
\hline y & 8911 & 9090 & 9477 & 9467 & 9552 & 10449 & 10918 & 11483 & wave3 & $-0,00006$ & $-0,00019$ & & & & & \\
\hline G & 0,3380 & 0,3223 & 0,3304 & 0,3346 & 0,3244 & 0,3179 & 0,3151 & 0,3176 & wave4 & 0,00027 & 0,00014 & 0,00033 & & & & \\
\hline $\mathrm{N}$ & 7307 & 7307 & 7307 & 7307 & 7307 & 7307 & 7307 & 7307 & wave5 & 0,00056 & 0,00044 & 0,00062 & 0,00029 & & & \\
\hline Clt-Cl1 & & 0,00013 & $-0,00006$ & 0,00027 & 0,00056 & 0,00167 & 0,00276 & 0,00330 & wave6 & 0,00167 & 0,00154 & 0,00173 & 0,00140 & 0,00111 & & \\
\hline ineq_in & & $-0,00027$ & $-0,00037$ & $-0,00012$ & $-0,00027$ & $-0,00044$ & $-0,00065$ & $-0,00062$ & wave7 & 0,00276 & 0,00263 & 0,00282 & 0,00249 & 0,00220 & 0,00109 & \\
\hline elas_in & & 0,00007 & 0,00022 & 0,00022 & 0,00025 & 0,00054 & 0,00067 & 0,00081 & wave8 & 0,00330 & 0,00317 & 0,00336 & 0,00303 & 0,00274 & 0,00163 & 0,00054 \\
\hline past_in & & 0,00002 & 0,00004 & 0,00006 & 0,00007 & 0,00009 & 0,00011 & 0,00013 & $\mathrm{~h}$ & & & & & & & \\
\hline ineq ot & & 0,00035 & 0,00014 & 0,00012 & 0,00050 & 0,00164 & 0,00274 & 0,00314 & $\begin{array}{l}\text { wave2 } \\
\end{array}$ & $-0,00132$ & & & & & & \\
\hline elas_ot & & 0,00000 & 0,00000 & 0,00000 & 0,00000 & 0,00000 & $-0,00001$ & $-0,00001$ & wave3 & $-0,00267$ & $-0,00135$ & & & & & \\
\hline past of & & $-0,00004$ & $-0,00009$ & 0,00000 & 0,00001 & $-0,00015$ & $-0,00010$ & $-0,00015$ & wave4 & $-0,00470$ & $-0,00338$ & $-0,00204$ & & & & \\
\hline ineq & & 0,00008 & $-0,00023$ & 0,00000 & 0,00023 & 0,00119 & 0,00209 & 0,00252 & wave5 & $-0,00604$ & $-0,00472$ & $-0,00337$ & $-0,00134$ & & & \\
\hline elas & & 0,00007 & 0,00022 & 0,00021 & 0,00025 & 0,00054 & 0,00067 & 0,00080 & wave6 & $-0,00577$ & $-0,00445$ & $-0,00311$ & $-0,00107$ & 0,00027 & & \\
\hline \multirow[t]{18}{*}{ past } & & $-0,00002$ & $-0,00005$ & 0,00006 & 0,00008 & $-0,00006$ & 0,00000 & $-0,00002$ & wave7 & $-0,00698$ & $-0,00565$ & $-0,00431$ & $-0,00227$ & $-0,00093$ & $-0,00120$ & \\
\hline & & & & & & & & & wave8 & $-0,00778$ & $-0,00646$ & $-0,00511$ & $-0,00308$ & $-0,00174$ & $-0,00201$ & $-0,00080$ \\
\hline & & & & & & & & & $\mathrm{y}$ & & & & & & & \\
\hline & & & & & & & & & wave2 & 179 & & & & & & \\
\hline & & & & & & & & & wave3 & 566 & 387 & & & & & \\
\hline & & & & & & & & & wave4 & 555 & 376 & -11 & & & & \\
\hline & & & & & & & & & wave5 & 640 & 461 & 74 & 85 & & & \\
\hline & & & & & & & & & wave6 & 1538 & 1359 & 972 & 982 & 897 & & \\
\hline & & & & & & & & & wave7 & 2006 & 1827 & 1440 & 1451 & 1366 & 468 & \\
\hline & & & & & & & & & wave8 & 2572 & 2393 & 2006 & 2017 & 1932 & 1034 & 566 \\
\hline & & & & & & & & & $\begin{array}{l} \\
\end{array}$ & & & & & & & \\
\hline & & & & & & & & & \begin{tabular}{|l|} 
wave2 \\
\end{tabular} & $-0,01579$ & & & & & & \\
\hline & & & & & & & & & wave3 & $-0,00768$ & 0,00811 & & & & & \\
\hline & & & & & & & & & wave4 & $-0,00345$ & 0,01234 & 0,00422 & & & & \\
\hline & & & & & & & & & wave5 & $-0,01369$ & 0,00210 & $-0,00601$ & $-0,01024$ & & & \\
\hline & & & & & & & & & wave6 6 & $-0,02018$ & $-0,00439$ & $-0,01251$ & $-0,01673$ & $-0,00650$ & & \\
\hline & & & & & & & & & wave7 & $-0,02291$ & $-0,00712$ & $-0,01523$ & $-0,01946$ & $-0,00922$ & $-0,00273$ & \\
\hline & & & & & & & & & wave8 & $-0,02041$ & $-0,00462$ & $-0,01273$ & $-0,01696$ & $-0,00672$ & $-0,00023$ & 0,00250 \\
\hline
\end{tabular}

Note: $\mathbf{C I}=C\left(h_{i t} \mid y_{i t}\right) ; \mathbf{h}=H_{t} ; \mathbf{y}=Y_{t} ; \mathbf{G}=G\left(y_{i t}\right) ; \mathbf{C I t}-\mathbf{C I 1}=C\left(h_{i t} \mid y_{i t}\right)-C\left(h_{i 1} \mid y_{i 1}\right) ;$ ineq_in: equation (2.20); elas_in: equation (2.14); past_in: equation (2.24); ineq_ot: equation (2.21); elas_ot: equation (2.15); past_ot: equation (2.25); ineq: sum of all ineq_-terms; elas: sum of all elas_-terms; past: sum of all past_terms; shaded: statistically significantly different from zero at $5 \%$ level. 
Appendix Table 15: detailed information for UK

\begin{tabular}{|c|c|c|c|c|c|c|c|c|c|c|c|c|c|c|c|c|}
\hline & wave1 & wave2 & wave3 & wave4 & wave5 & wave6 & wave7 & wave8 & \multicolumn{8}{|c|}{ PAIRWISE TESTS ON DIFFERENCE } \\
\hline \multicolumn{17}{|c|}{ 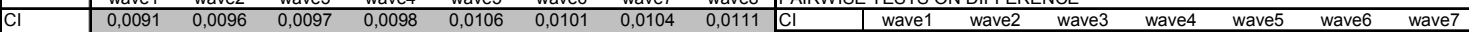 } \\
\hline h & 0,8860 & 0,8848 & 0,8851 & 0,8858 & 0,8859 & 0,8848 & 0,8856 & 0,8859 & wave2 & 0,0005 & & & & & & \\
\hline y & 13625 & 13767 & 14057 & 14781 & 15450 & 15319 & 16183 & 16652 & wave3 & 0,0006 & 0,0001 & & & & & \\
\hline G & 0,3004 & 0,3176 & 0,3011 & 0,2909 & 0,3068 & 0,3088 & 0,3071 & 0,3014 & wave4 & 0,0007 & 0,0002 & 0,0002 & & & & \\
\hline $\mathrm{N}$ & 5925 & 5925 & 5925 & 5925 & 5925 & 5925 & 5925 & 5925 & wave5 & 0,0015 & 0,0010 & 0,0010 & 0,0008 & & & \\
\hline Clt-Cl1 & & 0,00050 & 0,00057 & 0,00074 & 0,00155 & 0,00106 & 0,00135 & 0,00199 & wave6 & 0,0011 & 0,0006 & 0,0005 & 0,0003 & $-0,0005$ & & \\
\hline ineq_in & & $-0,00015$ & $-0,00025$ & $-0,00060$ & $-0,00033$ & $-0,00051$ & $-0,00063$ & $-0,00059$ & wave7 & 0,0013 & 0,0008 & 0,0008 & 0,0006 & $-0,0002$ & 0,0003 & \\
\hline elas_in & & 0,00004 & 0,00013 & 0,00033 & 0,00049 & 0,00046 & 0,00065 & 0,00075 & wave8 & 0,0020 & 0,0015 & 0,0014 & 0,0013 & 0,0004 & 0,0009 & 0,0006 \\
\hline past_in & & 0,00001 & 0,00002 & 0,00002 & 0,00003 & 0,00004 & 0,00004 & 0,00005 & h & & & & & & & \\
\hline ineq_ot & & 0,00056 & 0,00060 & 0,00090 & 0,00126 & 0,00095 & 0,00116 & 0,00168 & wave2 & $-0,0012$ & & & & & & \\
\hline elas_ot & & 0,00000 & 0,00000 & 0,00000 & 0,00000 & 0,00000 & 0,00000 & 0,00000 & wave3 & $-0,0009$ & 0,0003 & & & & & \\
\hline past_ot & & 0,00005 & 0,00008 & 0,00010 & 0,00010 & 0,00012 & 0,00013 & 0,00011 & wave4 & $-0,0002$ & 0,0009 & 0,0006 & & & & \\
\hline ineq & & 0,00041 & 0,00035 & 0,00029 & 0,00093 & 0,00044 & 0,00053 & 0,00109 & wave5 & $-0,0001$ & 0,0011 & 0,0008 & 0,0001 & & & \\
\hline elas & & 0,00004 & 0,00013 & 0,00033 & 0,00049 & 0,00046 & 0,00065 & 0,00074 & wave6 & $-0,0012$ & 0,0000 & $-0,0003$ & $-0,0010$ & $-0,0011$ & & \\
\hline past & & 0,00005 & 0,00010 & 0,00012 & 0,00013 & 0,00016 & 0,00017 & 0,00016 & wave7 & $-0,0004$ & 0,0007 & 0,0004 & $-0,0002$ & $-0,0003$ & 0,0007 & \\
\hline & & & & & & & & & wave8 & $-0,0001$ & 0,0010 & 0,0007 & 0,0001 & 0,0000 & 0,0011 & 0,0003 \\
\hline & & & & & & & & & $y$ & & & & & & & \\
\hline & & & & & & & & & wave2 & 142 & & & & & & \\
\hline & & & & & & & & & wave3 & 433 & 291 & & & & & \\
\hline & & & & & & & & & wave4 & 1156 & 1014 & 723 & & & & \\
\hline & & & & & & & & & wave5 & 1825 & 1683 & 1392 & 669 & & & \\
\hline & & & & & & & & & wave6 & 1694 & 1552 & 1261 & 538 & -131 & & \\
\hline & & & & & & & & & wave7 & 2559 & 2417 & 2126 & 1403 & 734 & 865 & \\
\hline & & & & & & & & & wave8 & 3028 & 2885 & 2595 & 1872 & 1203 & 1334 & 469 \\
\hline & & & & & & & & & G & & & & & & & \\
\hline & & & & & & & & & wave2 & 0,0172 & & & & & & \\
\hline & & & & & & & & & wave3 & 0,0007 & $-0,0165$ & & & & & \\
\hline & & & & & & & & & wave4 & $-0,0095$ & $-0,0267$ & $-0,0102$ & & & & \\
\hline & & & & & & & & & wave5 & 0,0064 & $-0,0108$ & 0,0057 & 0,0159 & & & \\
\hline & & & & & & & & & wave6 & 0,0083 & $-0,0088$ & 0,0077 & 0,0179 & 0,0020 & & \\
\hline & & & & & & & & & wave7 & 0,0067 & $-0,0105$ & 0,0060 & 0,0162 & 0,0003 & $-0,0017$ & \\
\hline & & & & & & & & & wave8 & 0,0010 & $-0,0162$ & 0,0003 & 0,0105 & $-0,0054$ & $-0,0074$ & $-0,0057$ \\
\hline
\end{tabular}

Note: $\mathbf{C I}=C\left(h_{i t} \mid y_{i t}\right) ; \mathbf{h}=H_{t} ; \mathbf{y}=Y_{t} ; \mathbf{G}=G\left(y_{i t}\right) ; \mathbf{C I t}-\mathbf{C I} 1=C\left(h_{i t} \mid y_{i t}\right)-C\left(h_{i 1} \mid y_{i 1}\right) ;$ ineq_in: equation (2.20); elas_in: equation (2.14);

past_in: equation (2.24); ineq_ot: equation (2.21); elas_ot: equation (2.15); past_ot: equation (2.25); ineq: sum of all ineq_-terms; elas: sum of all elas_-terms; past: sum of all past_terms; shaded: statistically significantly different from zero at $5 \%$ level. 